\title{
Social Cognition and Interpersonal Impairments in Trauma Survivors with PTSD
}

\author{
Thesis presented to the Faculty of Arts \\ of \\ the University of Zurich \\ for the degree of Doctor of Philosophy \\ by \\ Gabriela Nietlisbach \\ of Zurich
}

Accepted in the spring semester 2009 on the recommendation of Prof. Dr. Dr. Andreas Maercker and Prof. Dr. Markus Heinrichs

Zentralstelle der Studentenschaft der Universität Zürich Zurich, 2009 



\section{Abstract}

Background: Posttraumatic Stress Disorder (PTSD) is not only characterized by its symptom patterns but also by broad impairments in the social realm. The interaction between trauma survivors with PTSD and close friends and family, as well as the acceptance of social support, are of great importance for the further process following a traumatic experience. Nonetheless, trauma survivors with PTSD often show significant impairment in social interactions and relationships. For the retention of well functioning social interactions, different components of social cognition play an important role. Objectives: This thesis assessed differences in social cognition in trauma survivors with PTSD compared to non-traumatized controls. The first study assessed the following components of social cognition: empathy, Theory of Mind and empathic resonance. The second study experimentally investigated social exclusion as another part of social cognition using a ball tossing game to test effects of social exclusion as a possible maintenance factor for PTSD. Methods: In the first study, a sample of trauma survivors with PTSD $(\mathrm{N}=16)$ and healthy controls $(\mathrm{N}=16)$, completed objective tests such as the Reading the Mind in the Eyes Test, a faux-pas Test, an empathic resonance test and as a subjective measure, the Interpersonal Reactivity Index. The second study comprised an experimental paradigm (ball tossing) in a $2 \times 2$ design (group $\mathrm{x}$ experimental condition) to assess effects of social exclusion. Participants of the PTSD group ( $\mathrm{N}=16)$ and the control group $(\mathrm{N}=25)$ were randomly assigned to either the inclusion or exclusion condition. In addition to the Post Game Questionnaire, which assessed four fundamental human needs (belonging, self-esteem, control and meaningful existence), the measurement of the emotional well being (visual analogue scale) and a psychopathology scale (Brief Symptom Inventory) were also included. Results: In the first study, the PTSD group showed significantly lower empathic resonance and higher personal distress than the control group. The findings of the second study demonstrated the expected main effects for the majority of outcome measures (fundamental needs, emotional well being, and psychopathological assessments). Interaction effects were also found for psychopathological measures such as depression and anxiety. Conclusions: The results support the assumption of differences in social cognition such as lower empathy and higher impairments in mental health components after experiencing social exclusion in individuals with PTSD following the experience of trauma. 



\section{Zusammenfassung}

Theoretischer Hintergrund: Die Posttraumatische Belastungsstörung (PTSD) wird nicht nur durch ihr Symptommuster charakterisiert, sondern auch durch weitreichende Beeinträchtigungen im sozialen Bereich. Die Interaktion zwischen traumatisierten Menschen mit einer PTSD und engen Freunden und Familie und die Akzeptanz sozialer Unterstützung sind für den weiteren Verlauf nach einer Traumatisierung von grosser Bedeutung. Menschen mit PTSD berichten jedoch häufig über signifikante Beeinträchtigungen in sozialen Interaktionen und sozialen Beziehungen. Für die Aufrechterhaltung gut funktionierender sozialer Interaktionen spielen verschiedene Komponenten der Sozialen Kognition eine wichtige Rolle. Untersuchung: Im Rahmen dieser Dissertation wurden bei traumatisierten Menschen mit PTSD im Vergleich zu nicht-traumatisierten Kontrollpersonen Unterschiede in der Sozialen Kognition untersucht. Die erste Studie erhob die folgenden Komponenten der Sozialen Kognition: Empathie, Theory of Mind und empathische Resonanz. Die zweite Studie untersuchte die Effekte von sozialem Ausschluss als möglichen aufrechterhaltenden Faktor von PTSD experimentell mit einem Ballspiel. Methode: In der ersten Studie absolvierten PTSD-Probanden $(\mathrm{N}=16)$ und eine Kontrollgruppe $(\mathrm{N}=16)$ folgende objektive Tests: Reading the Mind in the Eye-Test, Faux-pas-Test, empathischer Resonanz-Test und als subjektive Messung den Fragebogen Interpersonal Reactivity Index. Die zweite Studie beinhaltete ein experimentelles Paradigma (Ballspiel) in einem 2x2 Design (Gruppe $\mathrm{x}$ experimentelle Bedingung), um Effekte von sozialem Ausschluss zu erfassen. Probanden der PTSD-Gruppe $(\mathrm{N}=16)$ und der Kontrollgruppe $(\mathrm{N}=25)$ wurden zufällig der Einschluss- oder Ausschlussbedingung zugewiesen. In Ergänzung zur Messung der Grundbedürfnisse Zugehörigkeitsgefühl, Selbstwert, Kontrolle und bedeutungsvolle Existenz (Post-GameQuestionnaire) wurde die emotionale Befindlichkeit (Visuelle Analogskala) und psychopathologische Masse (Brief Symptom Inventory) erhoben. Ergebnisse: In der ersten Studie zeigte die PTSD-Gruppe signifikant weniger empathische Resonanz und mehr persönliche Belastung als die Kontrollgruppe. Die Ergebnisse der zweiten Studie zeigten für die Mehrheit der erhobenen Variablen (Grundbedürfnisse, emotionale Befindlichkeit, Psychopathologie) die erwarteten Haupteffekte. Für Depression und Angst zeigten sich zudem Interaktionseffekte. Schlussfolgerung: Die Ergebnisse belegen die Annahmen vermuteter Unterschiede in der Sozialen Kognition. Menschen mit PTSD zeigen reduzierte Empathie und weisen nach einer Ausschlusserfahrung verstärkte Beeinträchtigungen in verschiedenen Aspekten des psychischen Wohlbefindens auf. 

Table of Contents ......................................................................... iv

Tables and Figures .................................................................... vi

Included Papers ........................................................................ vii

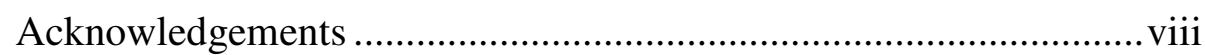




\section{Table of Contents}

1. INTRODUCTION

$\begin{array}{llr}1.1 & \text { Posttraumatic Stress Disorder } & 1\end{array}$

$\begin{array}{lll}1.1 .1 \quad \text { Maintaining and Recovery Factors } & 1\end{array}$

$\begin{array}{ll}\text { 1.1.2 Interpersonal Impairments } & 2\end{array}$

$\begin{array}{llr}\text { 1.2 Social Cognition } & 2\end{array}$

$\begin{array}{lll}\text { 1.2.1 Empathy and Theory of Mind } & 3\end{array}$

$\begin{array}{ll}\text { 1.2.2 Perceived Social Exclusion } & 4\end{array}$

$\begin{array}{llr}\text { 1.3 } & \text { Further Perspectives } & 5\end{array}$

2. SOCIAL COGNITION AND INTERPERSONAL IMPAIRMENTS IN TRAUMA SURVIVORS WITH PTSD $\quad 8$

$\begin{array}{rrr}2.1 & \text { Abstract } & 9\end{array}$

$\begin{array}{llr}2.2 & \text { Introduction } & 10\end{array}$

2.3 Research on Interpersonal Factors Impacting PTSD $\quad 11$

$\begin{array}{llr}2.3 .1 \quad \text { Social Support } & 11\end{array}$

\begin{tabular}{lr} 
2.3.2 Social Acknowledgment & 12 \\
\hline
\end{tabular}

2.3.3 Impairment of Intimate Relationships 13

2.4 New Frontiers in Social Cognition Research on PTSD 16

$\begin{array}{lll}2.4 .1 \quad \text { Understanding Others } & 16\end{array}$

$\begin{array}{ll}\text { 2.4.1.1 Theory of Mind } & 16\end{array}$

$\begin{array}{ll}\text { 2.4.1.2 Empathy } & 18\end{array}$

2.4.1.3 Understanding Others: A Neuronal Basis? 19

2.4.2 Perceived Social Exclusion $\quad 22$

$\begin{array}{ll}\text { 2.4.2.1 Theoretical Approaches } & 23\end{array}$

$\begin{array}{ll}\text { 2.4.2.2 Research Paradigms and Findings } & 24\end{array}$

2.4.2.3 Social Exclusion and Traumatic Experiences 25

$\begin{array}{llr}2.5 & \text { Discussion } & 25\end{array}$

3. ARE EMPATHIC ABILITIES IMPAIRED IN POSTTRAUMATIC STRESS DISORDER? $\quad 28$

$\begin{array}{lrr}3.1 & \text { Abstract } & 29\end{array}$

$\begin{array}{llr}3.2 & \text { Introduction } & \mathbf{3 0}\end{array}$

$\begin{array}{lll}3.2 .1 \quad \text { Empathy } & 30\end{array}$

$\begin{array}{ll}\text { 3.2.2 Empathic Abilities and PTSD } & 31\end{array}$

$\begin{array}{llr}3.2 .3 & \text { The Present Study } & 31\end{array}$

3.3 Materials and Methodology $\quad 32$

$\begin{array}{llr}3.3 .1 & \text { Participants } & 32\end{array}$

$\begin{array}{llr}3.3 .2 & \text { Measures } & 32\end{array}$

3.3.2.1 Assessment of PTSD $\quad 32$

3.3.3 Objective Tests of Resonance and Social Cognitive Functions 33

3.3.3.1 Empathic Resonance $\quad 33$

3.3.3.2 Reading the Mind in the Eyes Test - Revised Version (RMET; Mind-Reading) (Baron-Cohen,

Wheelwright, Hill, Raste, \& Plumb, 2001). 
3.3.3.3 Faux Pas Test (Baron-Cohen, O'Riordan, Stone, Jones, \& Plaisted, 1999) 34

3.3.3.4 Attribution Model $\quad 34$

3.3.4 Subjective Measure of Empathic Abilities $\quad 35$

3.3.4.1 Interpersonal Reactivity Index (IRI; Davis, 1983)

$\begin{array}{lll}\text { 3.3.5 Executive Functions } & 35\end{array}$

3.3.5.1 Verbal Fluency (Aschenbrenner, Tucha, \& Lange, 2000) 35

3.3.5.2 Figural Fluency (Regard, Strauss, \& Knapp, 1982) 36

3.3.5.3 Stroop Test (Jensen \& Rohwer, 1966; Stroop, 1935) 36

$\begin{array}{llr}3.3 .6 & \text { Procedure } & 36\end{array}$

$\begin{array}{lll}\text { 3.3.7 Data Analysis } & 36\end{array}$

$\begin{array}{llr}3.4 & \text { Results } & 37\end{array}$

$\begin{array}{lll}3.4 .1 & \text { PTSD Characteristics } & 37\end{array}$

$\begin{array}{lll}3.4 .2 & \text { Group Differences } & 37\end{array}$

3.4.3 Associations between Empathic Abilities and Psychopathology 40

$\begin{array}{llr}3.5 & \text { Discussion } & 41\end{array}$

$\begin{array}{llr}3.6 & \text { Conclusion } & 43\end{array}$

4. EFFECTS OF SOCIAL EXCLUSION IN TRAUMA SURVIVORS WITH PTSD 44

$\begin{array}{llr}4.1 & \text { Abstract } & 45\end{array}$

$\begin{array}{llr}4.2 & \text { Introduction } & 46\end{array}$

$\begin{array}{llr}4.3 & \text { Methods } & 47\end{array}$

$\begin{array}{llr}\text { 4.3.1 Participants } & 47\end{array}$

$\begin{array}{lll}\text { 4.3.2 } & \text { Assessments } & 47\end{array}$

$\begin{array}{lll}\text { 4.3.2.1 PTSD and related assessments } & 47\end{array}$

$\begin{array}{lll}\text { 4.3.2.2 Outcome Measures } & 48\end{array}$

$\begin{array}{llr}4.3 .3 & \text { Procedure } & 49\end{array}$

$\begin{array}{llr}\text { 4.3.3.1 Design and Experimental Manipulation } & 49\end{array}$

$\begin{array}{ll}\text { 4.3.3.2 Timeline } & 49\end{array}$

$\begin{array}{llr}\text { 4.3.4 Data Analysis } & 50\end{array}$

$\begin{array}{rrr}4.4 & \text { Results } & \mathbf{5 0}\end{array}$

$\begin{array}{llr}4.5 & \text { Discussion } & 55\end{array}$

5. REFERENCES 58 


\section{Tables and Figures}

Table 1: $\quad$ Existing lines of research that link trauma aftermath or PTSD to trauma-related phenomena, social cognitive constructs and future directions

Table 2: $\quad$ Sample Description

Table 3: $\quad$ Group Differences in Empathic Abilities (Objective and Self-Reported) and Executive Functioning

Table 4: $\quad$ Associations between Empathic Abilities and Psychopathology

Table 5: $\quad$ Group Differences in Social Exclusion Outcomes (adapted for life satisfaction and education)

Table 6: Associations between Social Exclusion Outcomes and Psychopathology $(\mathrm{N}=8$; PTSD exclusion group) 


\section{Included Papers}

Nietlisbach, G., \& Maercker, A. (in press). Social Cognition and Interpersonal Impairments in Trauma Survivors with PTSD. Journal of Aggression, Maltreatment \& Trauma.

Nietlisbach, G., \& Maercker, A. (2009). Effects of Social Exclusion in Trauma Survivors with PTSD. Submitted.

Nietlisbach, G., Maercker, A., Rössler, W., \& Haker, H. (2008). Are Empathic Abilities Impaired in Posttraumatic Stress Disorder? Submitted. 


\section{Acknowledgements}

Mein Dank geht an alle, die in irgendeiner Form zum Gelingen dieser Arbeit beigetragen haben. An erster Stelle danke ich den Probanden, die bereit waren, an den Studien teilzunehmen. Es ist insbesondere für traumatisierte Menschen ein grosser Schritt, sich an einer Trauma-Studie zu beteiligen. Dank gebührt auch meinen Lizenziandinnen, Christina Haeny, Tabea Müller und Nina Tauscher, die mit grossem Einsatz an den Studien mitgearbeitet haben.

Dr. Helene Haker und Prof. Dr. Wulf Rössler der Psychiatrischen Universitätsklinik Zürich danke ich für die interessante und anregende Zusammenarbeit im Rahmen der gemeinsamen Empathiestudie.

Mein weiterer aufrichtiger Dank gilt Prof. Dr. Markus Heinrichs für seine Bereitschaft zur Begutachtung dieser Arbeit.

Meinem Doktorvater, Prof. Dr. Dr. Andreas Maercker, danke ich sehr, dass er mir die Möglichkeit gegeben hat, mich in das spannende Gebiet der Traumaforschung zu vertiefen. Er ermutigte mich mit seinem Wissen und seiner Kreativität zur Entwicklung und Umsetzung eigener Forschungsideen. Zudem begleitete und motivierte er mich während meiner ganzen Dissertationszeit.

Dem ganzen Team der Fachrichtung Psychopathologie und Klinische Intervention, besonders Dr. Simon Forstmeier, Dr. Birgit Wagner, Dr. Hans Menning und Katharina Landis, danke ich für die konstruktive Zusammenarbeit und die freundschaftliche Atmosphäre während meiner dreijährigen Assistenzzeit. Meiner Arbeitskollegin Moyra Mortby, MSc, danke ich besonders für ihre wertvolle sprachliche Unterstützung dieser Arbeit und Dr. Birgit Kleim für ihr Engagement und ihre hilfreichen inhaltlichen Anregungen.

Meiner besten Freundin Maya sowie Alex, Eva, Dinah, all meinen anderen Freunden und meiner ganzen Familie bin ich sehr dankbar für die „,soziale Unterstützung“, deren Bedeutung so viel tiefer geht, als diese zwei Wörter beschreiben können.

Meinen Eltern, Rose-Marie und Guido Nietlisbach, danke ich von Herzen. Sie haben stets an mich geglaubt und mich jederzeit mit all ihren zur Verfügung stehenden Möglichkeiten gefördert und unterstützt. Das Wissen um ihr Dasein hat mich auch bei der Entstehung dieser Arbeit begleitet und bestärkt.

Meinem Partner Urs Baumgartner danke ich von ganzem Herzen für seine Unterstützung, seine Geduld und Ermutigungen und nicht zuletzt auch für sein wertvolles technisches Wissen, welches die Erstellung meiner Doktorarbeit in vielerlei Hinsicht erleichtert hat. Ihm ist diese Arbeit gewidmet. 




\section{Introduction}

The following thesis presents two studies about Posttraumatic Stress Disorder (PTSD) and the realm of social cognition. The aim of this work is to discover more about the extensive consequences of a traumatic event with subsequent Posttraumatic Stress Disorder. Therefore, the focus is on possible changes of social cognitive processes which are relevant for successful social interactions. The first study compared various facets of social cognition between participants with PTSD and non-traumatized participants, while the second study focused on effects of self-perceived social exclusion as another possible maintaining factor for PTSD.

\subsection{Posttraumatic Stress Disorder}

Posttraumatic Stress Disorder (PTSD) is in the current DSM-IV (American Psychiatric Association, 1994) as well as in ICD-10 (Dilling, Mombour, \& Schmidt, 2000) defined in terms of a first stressor criterion in which a person has had a traumatic experience in which they experienced, witnessed or were confronted with an event which involved death (or the threat of death), serious injury, or a threat to the physical integrity of another person. The second stressor criterion requires that the traumatic event must be associated with the experience of intense fear and the feeling of helplessness. The characteristic symptoms resulting from the exposure to extreme trauma include (a) persistent reexperiencing of the traumatic event (i.e. nightmares), (b) avoidance of stimuli associated with the trauma (i.e. numbing) and (c) increased arousal (sleep disturbance). A diagnosis of chronic PTSD (as examined in the two present studies) is given when the symptoms last three or more months.

\subsubsection{Maintaining and Recovery Factors}

The development and process of Posttraumatic Stress Disorder is influenced by intrapersonal factors such as age, gender and education levels, and also by further aspects such as time passed since trauma and the intensity of trauma exposure (Brewin, Andrews, \& Valentine, 2000). In addition to these predictors, interpersonal factors such as social support, social acknowledgment and the existence and quality of intimate relationships, are known to affect the state of human health (Bradley \& Cartwright, 2002) and the development and maintenance of PTSD (Cook, Riggs, Thompson, Coyne, \& Sheikh, 2004; Müller, Moergeli, 
\& Maercker, 2008; Ozer, Best, Lipsey, \& Weiss, 2003). According to the Social Facilitation Model of PTSD (Maercker, 2008a; Maercker, 2008b), social factors such as empathic exchange and the avoidance of social exclusion are important components for further PTSD.

\subsubsection{Interpersonal Impairments}

Beyond the classified symptoms (American Psychiatric Association, 1994), PTSD patients report increased problems in social domains. In particular, trauma survivors with PTSD often report impairment in social interactions and relationships (Cook, Riggs, Thompson, Coyne, \& Sheikh, 2004). The interaction between trauma survivors with PTSD and close friends and family, as well as the acceptance of social support, are known to be of great importance in order to process a traumatic experience (Schnurr, Lunney, \& Sengupta, 2004). However, relationships with close relatives and intimate partners are often especially difficult and a source of conflict following the traumatic event (Riggs, Byrne, Weathers, \& Litz, 1998). Some PTSD symptoms such as emotional numbing and arousal have been discussed as possible reasons for these impairments (Johnson \& Greenberg, 1994). However, it remains unclear which other reasons contribute to these impairments. This raises the question, whether traumatic events not only lead to the known symptoms of PTSD, or whether they additionally contribute to changes in particular facets of social cognition which are relevant to successful social interaction.

\subsection{Social Cognition}

Social cognition involves subjective processes that affect not only the interaction between individuals, but also individual perception of social interactions (Moskowitz, 2005). Research has focused on the effects of social support and social acknowledgment in relationships between individuals, and on impaired intimate relationships after a traumatic experience. The focus has mainly been on the "sender's viewpoint", with social cognition research considering the "receiver's viewpoint" (i.e. the investigation of subjective perceptions of social interactions) as well as the prerequisites for social interactions (i.e. components of social cognition such as the ability for empathy, a stable Theory of Mind (ToM) and the capacity for resonance). These are all essential aspects for well functioning social relationships. 


\subsubsection{Empathy and Theory of Mind}

Empathy is defined as the ability to share and infer emotional experiences of others (Gallese, 2003). It is not a unitary function, but comprises the elements of empathic resonance, emotional empathy and cognitive empathy (Blair, 2005; De Vignemont \& Singer, 2006). Empathic resonance is the phenomenon in which a person unconsciously mirrors the motor actions of another and is a basic prerequisite for human interaction. As one component of empathy, this shared representation serves as a basis for sharing other people's physiological and emotional states (Preston \& De Waal, 2002). Some research indicates that resonance is a bottom-up contribution to emotional or cognitive empathy and is mediated by shared representation in the mirror neuron system (Keysers \& Gazzola, 2007).

Theory of Mind (ToM) comprises a range of mental abilities that are relevant to successful social interaction. These abilities include cognitions which make it possible for humans to recognize, understand, explain and communicate own and other people's behaviors and emotions, and can therefore be seen as cognitive part of empathy, which is used to understand and explain the mental state of others (Baron-Cohen, Tager-Flusberg, \& Cohen, 2000). A specific aspect of ToM is "mind-reading" (Baron-Cohen, Wheelwright, Hill, Raste, \& Plumb, 2001). ToM includes the development of mental perspective-taking as well as the recognition of more complex "faux pas" situations (Brune \& Brune-Cohrs, 2006). A faux pas occurs when a person says something they should not have, not knowing or realizing that they should not have said it. Reduced empathic abilities can have multiple effects on relationships. As mentioned, the exchange with others has many potential benefits for trauma victims with PTSD. However, trauma survivors with PTSD often show impairments in interpersonal interactions which may prevent such benefits being achieved (Riggs, Byrne, Weathers, \& Litz, 1998).

The first study hypothesized that traumatic experiences lead, not only to known PTSD symptoms, but also to empathic ability impairment and difficulties in sharing affective, emotional or cognitive states. This hypothesis was tested through the comparison of a PTSD group $(\mathrm{N}=16)$ and a non-traumatized control group $(\mathrm{N}=16)$ on the following empathic abilities: empathic resonance (contagion) and social cognitive functions such as "mind-reading", assessed through the Reading the Mind in the Eyes Test (RMET; Baron-Cohen, Wheelwright, Hill, Raste, \& Plumb, 2001) and the Interpersonal Reactivity Index (IRI; Davis, 1983), a selfreported measure of empathy. The aim of the study was to assess group differences in objective and subjective empathic abilities and the severity of PTSD was correlated with 
impairments in empathic abilities. A main finding of this study was that the PTSD group showed lower empathic resonance relative to non-traumatized controls, while other social cognitive functions demonstrated no clear indications of impairment. In terms of self-reported empathic abilities (IRI), individuals with PTSD showed significantly higher personal distress, which could either be a consequence of the trauma itself or a potential coping strategy. In relation to the interpersonal impairments in trauma survivors with PTSD, the current findings appear to reflect a fundamental adjustment of non-reflective responses to contagious social information. This may affect interpersonal interactions in a variety of ways.

\subsubsection{Perceived Social Exclusion}

Humans are social creatures and the desire for positive social relationships is one of the most fundamental and universal human needs (K.D. Williams, 2007). Ostracism and social exclusion include social cognitions which involve destructive or harmful processes such as perceived social exclusion (Twenge, Baumeister, Tice, \& Stucke, 2001). Social exclusion is an act of ostracism, which is defined as being excluded, alone or isolated, and in which, at times, dislike is declared explicitly (Twenge, Baumeister, Tice, \& Stucke, 2001). Ostracism and social exclusion are very old, powerful and ubiquitous phenomena in mankind and to date, every aspect of day-to-day life has the potential for some form of social exclusion (K.D. Williams \& Zadro, 2001). An experimental manipulation has been proposed by Williams and colleagues to induce self-perceived feelings of social exclusion through the introduction of a ball tossing game (Williams, 2001; Williams \& Sommer, 1997). Responses to social exclusion and ostracism can be diverse and range from decreased prosocial behavior to increased aggression (Williams, 2007). In his need threat model, Williams (1997) proposed that as a main effect, ostracism threatens the four fundamental needs of belonging, control, self-esteem and meaningful existence. Trauma survivors with PTSD often report social stigmatization and isolation (Borja, Callahan, \& Long, 2006). Some features of posttraumatic symptomatology (e.g. feelings of alienation or chronic hyperarousal) and interpersonal factors (e.g. social rejection due to the traumatic experience) may increase and generalize social exclusion experiences in individuals with PTSD. Such experiences may be an additional emotional burden for trauma victims and pose another maintaining factor for PTSD.

The second study applied the ball tossing paradigm in a face-to-face version to investigate more closely, the phenomenon of social exclusion in traumatized individuals. Since the ball tossing game has already shown large effects in healthy individuals (Williams, 
2007), small additional effects were expected for trauma survivors with PTSD. A PTSD group $(\mathrm{N}=16)$ and a non-traumatized control group $(\mathrm{N}=25)$ were assessed in a $2 \times 2$ (group $\mathrm{x}$ experimental condition) design in which the experimental condition comprised a randomly assigned inclusion or exclusion condition in the ball tossing game (covertly implemented as part of the procedure). In addition to the Post Game Questionnaire which assesses four fundamental needs (Williams, 1997; Williams \& Sommer, 1997), emotional well-being was measured before and after the ball tossing game and the Brief Symptom Inventory (Derogatis, 1992), a psychopathological scale, was also included. The results demonstrated the expected main effects for the majority of outcome measures as assessed by the Post Game Questionnaire, the Well Being Scale and the Brief Symptom Inventory. The clearest findings of the current study were the interaction effects of psychopathological measures of depression and anxiety which indicated social exclusion manipulation to lead to extensive impairments of mental health components in trauma survivors with PTSD. Accordingly, psychoeducation and the development and application of particular interventions may protect trauma survivors with PTSD against further psychosocial impairments and other mental health problems.

\subsection{Further Perspectives}

Interpersonal impairments are a prevalent phenomenon in trauma survivors with PTSD. Changes in components of their social cognition may explain a part of the various causes of their social problems. It is known that positive social interactions such as social support and social acknowledgment affect further process after a traumatic experience positively (Laffaye, Cavella, Drescher, \& Rosen, 2008; Müller, Moergeli, \& Maercker, 2008). Within intimate relationships, a traumatic experience of one partner can lead to extensive interpersonal interaction stress. In terms of therapeutic psychoeducation, trauma survivors, their intimate partners and family members, should be made aware of the extensive consequences that reach beyond the classified symptoms of the experience of a traumatic event.

Apart from the two studies presented in this thesis, little is known about differentiated effects of social cognition components following a traumatic experience. Social cognition comprises the perception and processing of socially relevant information and situations (including self-acting and controlled information processes). The Social Facilitation Model of Posttraumatic Stress Disorder by Maercker (2008a; 2008b) includes the interaction of aspects such as "self", "others" and "world" and forms the basis for these two studies. This 
interaction either increases or decreases the symptoms and course of PTSD and in accordance with this model, a basic differentiation can be made between the perception of the person himself ("self") and their social peers ("others"). For well functioning intimate relationships, the viewpoint of trauma survivors is as important as the viewpoint of the socially involved people. It is therefore important that future research considers both these aspects of social interactions.

Based on the thesis' findings, more research is needed to examine the moderator differences of age, gender and variation throughout the life-span in terms of social cognition aspects (e.g. mental health impairments after the experience of social exclusion). The influence of trauma related moderators such as the difference between manmade and natural disasters or singular versus multiple trauma experiences must also be considered. Future research should also strive to ascertain whether there is a high risk population for particular social cognitive impairments amongst trauma survivors with PTSD and particular attention should also be paid to persistent social exclusion effects in order to determine the length of such effects, rather than solely focusing on immediate reactions (Zadro, Boland, \& Richardson, 2006).

Further research is also required in terms of mediators. In particular, the question of pathways must be addressed. In our social exclusion study it was not possible to ascertain individual coping-strategies in dealing with the experience of social exclusion. Future studies should consider mediation factors such as possible avoidance behaviors or cognitive appraisals. An example for this can be found in a study by Krill and colleagues (2008). The authors connected effects of ostracism with individual empathic abilities and they examined how empathizing and systemizing cognitive styles (Wakabayashi et al., 2006) account for variation in the experience of social exclusion during the online version of the ball tossing game. It has been reported that empathizers report feeling less in control (one of the four fundamental needs implemented by Williams and colleagues (1997) and which was presented in the second study) when compared to systemizers during the ball tossing game (regardless of whether being in the exclusion or inclusion condition). These findings suggest that individuals with high empathizing score struggle more with lack of control when involved in a situation where they cannot influence the social interaction in which they are involved in. Prospective studies with potential high risk populations are needed to examine how components of social cognition changes after a traumatic experience. Such studies should 
focus on the idea that a traumatic experience may lead to feelings of loss of control and that high empathizing scores may be another risk factor for PTSD. In particular, the unconscious part of empathy (more precisely empathic resonance) is reduced in trauma survivors with PTSD in comparison to non-traumatized controls. Future studies should therefore focus on correlations between changes and their consequences in terms of empathic abilities before and after a traumatic experience.

Apart from the therapeutic use of psychoeducation, there is a need for the development and implementation of particular intervention programs within the therapy. Such therapeutic measures should take into account differences in emotional resonance after a traumatic experience, mental health impairments after social exclusion experiences and further research on social cognition changes in trauma survivors with PTSD. Singer and colleagues (personal communication) are currently developing a particular training method through which to improve empathy. It should be possible to adapt this training method for individuals with PTSD as well as for their relatives. Furthermore, future research should examine whether particular interventions for trauma survivors and their intimate partners regarding social cognitive processes influence the therapeutic success on one hand and lead to less impairments within the intimate relationships on the other hand. 


\title{
2. Social Cognition and Interpersonal Impairments in Trauma Survivors with PTSD
}

\author{
Nietlisbach, G. \& Maercker, A. \\ Journal of Maltreatment, Aggression \& Trauma (in press)
}




\subsection{Abstract}

Trauma survivors with posttraumatic stress disorder (PTSD) often experience psychosocial problems. This article reviews interpersonal factors such as social support, social acknowledgment, and interpersonal impairment that are relevant to the development and maintenance of PTSD. Furthermore, it considers the possible impact of social cognition on PTSD. The capacity to empathize (empathy) and the existence of an individual Theory of Mind are fundamental to human social interaction. We raise the question of whether traumatic experiences may lead to change in the social cognition of traumatized individuals. The possible effects of perceived social exclusion as a maintenance factor for PTSD are also discussed. 


\subsection{Introduction}

Humans are profoundly social creatures. Social integration and interaction are basic human needs (Williams, 2007). Charuvastra and Cloitre (2008) have recently considered the role of social phenomena in the risk for and recovery from posttraumatic stress disorder (PTSD), focusing on the role of social bonds. The present article extends this approach in a number of respects. The interaction between trauma survivors with PTSD and close friends and family, as well as the acceptance of social support, are known to be of great importance for the processing of the traumatic experience (Schnurr, Lunney, \& Sengupta, 2004). Yet trauma survivors with PTSD often show impairment in social interactions and relationships (Cook, Riggs, Thompson, Coyne, \& Sheikh, 2004). Relationships with close relatives and intimate partners are often especially difficult and conflicted after the traumatic event (Riggs, Byrne, Weathers, \& Litz, 1998).

An important question is whether traumatic events not only lead to the known symptoms of PTSD or whether they contribute additionally to changes in particular facets of social cognition which are relevant for successful social interactions? Traumatic experiences may impact and may be impacted by social cognitive processes as already shown by various lines of existing research. For instance, DePrince (2005) examined the impact of betrayal trauma on social reasoning. The author suggests alterations in social cognition to be a possible mechanism for revictimization risk related to dissociation. Ullman (2003) reviewed social reactions to trauma disclosure and emphasized that negative social reactions to trauma disclosure can have harmful consequences for trauma survivors.

The aim of the current article is to examine the possible connections between PTSD and impairment of particular facets of social cognition and to present suggestions for future research in this field. PTSD was chosen as the main focus even though it is not the most likely reaction after a trauma, but because of it is a characteristic phenotypical expression following trauma. It was also chosen in accordance with the authors' previous experiences in PTSD. This article will first review the findings on interpersonal factors that are known to be relevant to the development and maintenance of PTSD, namely social support, social acknowledgment, and interpersonal impairment. Then we will discuss changes in social cognition that might theoretically be associated with PTSD. Social cognition involves the perception, interpretation, and processing of all information relating to a person's social environment and relationships, and is thus often used as an umbrella term (Moskowitz, 2005). In this article, we distinguish four aspects of social cognition which are all relevant for successful social interactions: a 
cognitive element in the sense of Theory of Mind (ToM), an affective element in the sense of empathy, the unconscious capacity for emotional resonance, and experiences of perceived social exclusion. On the basis of these considerations, we suggest that people with PTSD may be unable to recognize social signals in the same way as people without PTSD, making them unable to respond appropriately to social signals. Accordingly, we propose that changes in social cognition are one of several possible mechanisms that may impair the maintenance of close social relationships in people with PTSD.

\subsection{Research on Interpersonal Factors Impacting PTSD}

Interpersonal factors such as social support, social acknowledgment, and the existence and quality of intimate relationships are known to affect the state of human health, in general (Bradley \& Cartwright, 2002), and the development and maintenance of PTSD, in particular (Ozer et al., 2003; Jones, Müller, \& Maercker, 2006; Cook et al., 2004).

Accordingly, theoretical models of PTSD development (Brewin, 2005; Brewin, Andrews, \& Valentine, 2000; Maercker, 2003) are not restricted to biological and psychological factors, but also include interpersonal and social factors. According to these models, the way in which survivors are treated by their social environment after a traumatic event affects trauma processing and, in particular, PTSD symptomology (Maercker \& Müller, 2004). In this section, we review research findings on how social support, social acknowledgment, and impairment of intimate relationships can influence the development and maintenance of PTSD.

\subsubsection{Social Support}

A wide range of research has established that social support is an important psychosocial resource that promotes physical and psychological health (Bradley \& Cartwright, 2002). The association between social support and PTSD has been extensively studied. Some studies indicate that social support is a protective factor against PTSD, whereas others suggest that a lack of social support increases the risk of PTSD. A meta-analysis examining the risk factors related to PTSD showed that lack of social support is one of the strongest predictors of PTSD (Brewin, Andrews, \& Valentine, 2000). Consistently, social support has been found to be among the strongest predictive factors of PTSD, with an effect size of 0.29 (Ozer et al., 2003). The results of numerous studies examining various trauma groups also indicate that 
social support is involved in the development and maintenance of PTSD (Guay, Billette, \& Marchand, 2006; Scarpa, Haden, \& Hurley, 2006; Schnurr, Lunney, \& Sengupta, 2004). Retrospective studies of survivors of natural disaster (Cook \& Bickman, 1990) and combat (Jankowski et al., 2004; Solomon, Waysman, \& Mikulincer, 1990) indicate that social support is significantly related to the severity of PTSD symptoms, with lower levels of social support being associated with more severe PTSD symptoms. A recent study (Scarpa, Haden, \& Hurley, 2006) tested the moderating role of social support on the relationship between community violence victimization and severity of PTSD. Significant moderating effects were found which indicated a stronger relationship between 'victimization and heightened PTSD severity' at 'high levels of perceived friend support and disengagement' (p. 446). These findings suggest 'the protective function of friend support' to 'break down at increasing levels of victimization', while the 'risk for negative outcome' is increased by avoidant coping styles (p. 446).

Social support thus appears to play an important role in coping with stress in general and with traumatic stress in particular (Riggs et al., 1998; Solomon, Waysman, \& Mikulincer, 1990). Seeking social support is an active coping method for dealing with traumatic stress and, as mentioned above, significantly helps to protect against PTSD (Ozer, Best, Lipsey, \& Weiss, 2003). In their review, Olff, Langeland, and Gersons (2005) looked at individual differences in trauma survivors' emotional and neurobiological reactions to a psychosocial stressor. They identified cognitive appraisal and coping factors as potential sources of individual differences in neuroendocrinological stress response and in subsequent mental health outcomes. Thus, seeking social support can be associated with the process of disclosure, whereas lack of disclosure might impede helpful social interventions. Ullman (2003) examined social reactions to child sexual abuse disclosures in childhood and adulthood. Evidence was presented which showed that negative social reactions are harmful for the well-being of trauma survivors.

\subsubsection{Social Acknowledgment}

Social acknowledgment as a victim or survivor is defined as a victim's experience of positive reactions from society that show appreciation for the victim's unique state and recognition of the victim's current difficult situation (Maercker \& Müller, 2004). Whereas the psychological construct of social support is generally limited to the active emotional and instrumental aid provided by the close social environment, that of social acknowledgment encompasses a wider social environment, including colleagues and neighbors as well as local 
authorities, clergy, and the media (Müller \& Maercker, 2006). Together with social support, social acknowledgment may well affect the victim's mental state and thus influence the further processing of the traumatic experience (Jones, Müller, \& Maercker, 2006; Maercker \& Mehr, 2006; Müller, Moergeli, \& Maercker, 2008).

A study with former political prisoners in East Germany found that victims deprived of social acknowledgment have a heightened risk for chronic PTSD symptoms. Social acknowledgment and disclosure explained up to $11 \%$ of the variance in PTSD, above and beyond known predictors. Such predictors include age, gender, education levels, time passed since trauma and the intensity of the trauma exposure (Brewin, Andrews \& Valentine, 2000).

At the same time, trauma survivors with PTSD generally receive less social acknowledgment than trauma survivors without PTSD (Maercker \& Müller, 2004; Müller \& Maercker, 2006).

Many processes of appraisal and attribution influence the further processing of the traumatic event as well as the behavior of the social environment. The measure of accordance between the victim's experience and its appraisal by the victim's family or extended social environment may considerably impact the victim's ability to adjust to the trauma (Cordova, Cunningham, Carlson, \& Andrykowski, 2001). Gray, Pumphrey, and Lombardo (2003) found a significant association between pessimistic attributional style, measured by the attributional style questionnaire (ASQ), and severity of PTSD symptoms.

These results highlight the important potential benefits of exchange with others and of social support and understanding for trauma victims. However, trauma victims with PTSD show impairments in interpersonal functioning and difficulties interacting within intimate social relationships that may dilute or nullify these benefits.

\subsubsection{Impairment of Intimate Relationships}

Social support and social acknowledgment are thus important in the processing of trauma. In particular, lack of social support is the strongest predictor of PTSD (Brewin, Andrews, \& Valentine, 2000). Do these findings imply that close relationships are important, regardless of their quality? In this section, we focus on another important interpersonal factor in the context of PTSD: the quality of intimate relationships. Traumatic experiences can have a major impact on interpersonal relationships. In particular, a trauma may have detrimental effects on self-awareness, intimacy, sexuality, and communication, all of which are key 
elements in the maintenance of healthy interpersonal relationships (McFarlane \& Bookless, 2001).

People with PTSD often report lasting impairments in their relationships with partners and family. However, few studies have yet investigated the effect of trauma on intimate relationships. Most critically, the causal direction of the association between interpersonal impairments and PTSD symptomatology has not yet been determined (Cook et al., 2004; Riggs et al., 1998).

Cook et al. (2004) examined the association of PTSD with the quality of intimate relationships among male World War II ex-prisoners of war. Over 30\% of those with PTSD reported relationship problems compared with only $11 \%$ of those without PTSD. Ex-prisoners of war with PTSD reported poorer adjustment and poorer communication with their partners and more difficulties with intimacy. Emotional numbing was significantly associated with relationship difficulties. Previous studies of war veterans also found them to have serious difficulties maintaining intimate relationships (Johnson et al., 1996; Solomon, Mikulincer, Freid, \& Wosner, 1987). Over two thirds of male Vietnam veterans with PTSD reported clinically significant levels of relationship distress compared with only about one third of non-PTSD veterans (Riggs et al., 1998). In Riggs et al.'s study, the Dyadic Adjustment Scale (Spanier, 1976) was used to assess clinically significant levels of relationship distress. According to Heyman, Sayers and Bellack (1994) scores of less than 98 comprise clinically significant levels of relationship distress. Furthermore, the results showed that emotional numbing symptoms were more strongly related to relationship quality than were effortful avoidance symptoms. Riggs et al. (1998) suggested several possible reasons for individuals with PTSD experiencing difficulties within intimate relationships. First, emotional expression plays an important role in the intimate exchanges that are integral to well functioning relationships (Johnson \& Greenberg, 1994). Hence, it seems likely that symptoms of emotional numbing (i.e., loss of interest in activities, impaired affect, detachment from others) contribute to relationship distress. Second, hyperarousal symptoms of PTSD, such as irritability and concentration problems, may adversely affect the way that couples approach problems, increasing conflicts and distress within the relationship. In turn, difficulties in intimate relationships may contribute to the persistence of post-traumatic symptoms (Davidson, Hughes, Blazer, \& George, 1991). Similar findings have been reported for people who developed PTSD following motor vehicle accidents (Blanchard, Hickling, Taylor, \& Loos, 1995) and for firefighters who battled huge bushfires in Australia (McFarlane, 1988). 
Previous studies have indicated that emotional numbing-i.e., feelings of alienation and indifference-is particularly detrimental to relationships. PTSD research has taken various different perspectives on the concept of emotional numbing. Yoshihama and Horrocks (2005) investigated emotional numbing symptoms in a community-based random sample of immigrant women and US-born immigrant offspring who had experienced interpersonal victimizations, such as childhood abuse, intimate partner violence or violence perpetrated by non-intimates. In their study, a modified self-report form from the National Women's Study PTSD Module was used to assess respondents' experience of post-traumatic stress symptoms related to DSM-IV (American Psychiatric Association, 1994). The central findings of this study suggested a relationship between emotional numbing and age, place of birth and social support. The association of social support with lower emotional numbing suggested that low social support satisfaction may be related to feelings of being cut off from their support network. This in turn can be associated with the disruption of social support systems, language barriers and lack of familiarity due to immigration.

Regarding another aspect of interpersonal relationships, DePrince (2005) examined the impact of trauma on social reasoning. The ability to detect violations in social contracts and within the ability to avoid harmful relationships was found to be impaired in young adults who have with experienced of revictimization when compared to young adults without the experience of revictimization. Furthermore, the results demonstrated that pathological dissociation significantly predicted errors on social contract and precautionary problems on the Wason Selection Task (Cosmides, 1989). Alterations in social cognition could be a possible mechanism for revictimization risk and that is related to pathological dissociation (DePrince, 2005). DePrince (2005) argued that according to the betrayal trauma theory (Freyd, 1994), detecting violations of social contracts may be counter-productive to survival, especially when a victim is dependent on a perpetrator. The victim may develop a compromised capacity to detect violations in social exchange rules, which in turn may increase risks for later victimization due to problems in detecting violations of social contracts (DePrince, 2005, p. 125).

Having outlined interpersonal factors relevant to the development and maintenance of PTSD, we now discuss different processes of social cognition which are important for successful social interactions, describe possible methods for examining these processes and present relevant clinical findings from fields other than trauma research. 


\subsection{New Frontiers in Social Cognition Research on PTSD}

Social cognition involves subjective processes that affect not only interaction between individuals, but also individual perceptions of social interactions (Moskowitz, 2005). Up to this point, research has focused on the effects of social support and social acknowledgment on relationships between individuals, and on the quality of intimate relationships after a traumatic experience. Furthermore, the focus has been on the "sender's viewpoint." Social cognition research encompasses not only the "sender's viewpoint" as a necessary prerequisite for social interaction, but also the "receiver's viewpoint." In other words, social cognition research investigates how subjective perceptions of social interactions are formed, as well as the prerequisites for social interaction: the capacity for emotional resonance, the development of Theory of Mind (ToM), and the ability to empathize (Moskowitz, 2005).

\subsubsection{Understanding Others}

To date, social psychology and social neuroscience have, for the most part, addressed different aspects of social cognition. Two central concepts, empathy and the capacity for ToM, are important topics of social cognition research in both fields. ToM is defined as "the attribution of mental states, such as desires, intentions and beliefs, to others" (Frith, 1999; p.1692), whereas empathy has been described as the ability to infer and share the emotional experiences of others (Gallese, 2003).

\subsubsection{Theory of Mind}

ToM concerns a range of mental abilities that are relevant for successful social interactions, including cognitions that make it possible for humans to recognize, understand, explain, predict, and communicate their own behavior and emotions or the behavior and emotions of others (Baron-Cohen, Tager-Flusberg, \& Cohen, 2000). The terms "mindreading" and "mentalizing" are used synonymously in literature. The term "theory of mind" was originally proposed by two primatologists to suggest that chimpanzees may be capable of inferring the mental states of their conspecifics (Premack \& Woodruff, 1978). Later on, child psychologists adopted the term to describe the ontogenetic development of mental perspective-taking in infants and young children (Leslie, 1987).

Humans develop ToM at around four years of age. At this age, children become aware that the same facts and circumstances may be presented in different, even contradictory ways. 
Although scientific understanding of children's acquisition of ToM abilities is growing, fairly little is known about the development of ToM in adult humans. Consensus has not yet been reached on how, if at all, human ToM capacities change over the adult lifespan (Brune \& Brune-Cohrs, 2006).

How have ToM abilities been tested? The "gold standard" is the classic Sally and Anne Test (Wimmer \& Perner, 1983). This test experimentally creates a situation in which a test person has to distinguish his or her own knowledge that an object has been hidden by one person (Anne) in the absence of another person (Sally) from the knowledge of the others involved. The deciding question is where Sally would look for the object on her return: in the place she left it, or in the place Anne put it. Children under the age of four usually perform poorly on this first-order false belief task.

Recognition of "faux pas" situations is even more complex (Brune \& Brune-Cohrs, 2006). A faux pas occurs when a person says something she should not have said, not knowing or not realizing that he or she should not have said it. Recognizing faux pas requires a developmentally advanced ToM ability because it requires simultaneous representation of two mental states: that of the person committing the faux pas, and that of the second person involved, who may feel hurt or irritated (Brune \& Brune-Cohrs, 2006). In experimental research, respondents are shown short video sequences about faux pas in daily life situations and control stories (Baron-Cohen et al., 1999). After each story, respondents are asked a few questions about the stories. Faux pas stories were originally used to examine Asperger syndrome and autism (Baron-Cohen et al., 1999), and have since been used to find out more about social cognition in patients with dementia and Alzheimer's disease (Gregory et al., 2002; Lough \& Hodges, 2002).

Baron-Cohen and colleagues have developed and revised another test of ToM called "Reading the Mind in the Eyes" (RMET; (Baron-Cohen, Wheelwright, Hill, Raste, \& Plumb, 2001). Respondents are asked to infer the mental states of persons of whom only the eye area is visible. The RMET is postulated to assess an advanced aspect of ToM, called mind reading (Baron-Cohen et al., 1997), by testing the ability to recognize complex emotions and mental states from eye expression alone. For instance, the RMET has been used to investigate ToM in clinical depression (Lee, Harkness, Sabbagh, \& Jacobson, 2005) and in psychopathic individuals (Richell et al., 2003).

For the most part, ToM deficit hypothesis has been applied to autism, schizophrenia, and personality disorders, in particular psychopathy (Brune, 2001). Its relation to other psychopathological conditions and psychiatric disorders is less clear (Brune \& Brune-Cohrs, 
2006). For instance, there has been little research on the effects of ToM in the context of affective disorders and PTSD.

\subsubsection{Empathy}

In addition to recognizing the mental states of others, humans can also empathize with others, which means sharing their feelings and emotions in the absence of any direct emotional stimulation to themselves (Singer, 2006). Empathy is defined as a vicarious experience of others' emotions. It is assumed to be crucial for many forms of adaptive social interactions (Spinella, 2005). Empathy is distinguished from other forms of social cognition by the centrality of the understanding of emotion (Vollm et al., 2006). As mentioned above, ToM or the ability to mentally represent other peoples' mental processes can be defined as a cognitive component of person-related social cognition, whereas empathy, with its focus on emotional topics, is often seen as an affective component. The subcomponents of emotional and cognitive empathy are sometimes distinguished (Jolliffe \& Farrington, 2004). In everyday usage, empathy is usually understood to be a complex, multilevel construct reaching from simple forms of emotional contagion to complex forms of empathic perspective-taking associated with other-regarding prosocial behavior (Decety \& Jackson, 2004).

Singer (2006) has suggested that abilities to understand other peoples' thoughts and to share their affects display different ontogenetic trajectories, with empathy developing much earlier than mentalizing abilities. Empathy relies on limbic structures that develop earlier in ontogeny, whereas mentalizing abilities rely on structures that are among the last to fully mature.

Empathy has been widely measured by self-rating scales. Perhaps the best-known measure is Davis' interpersonal reactivity index (IRI), which covers both cognitive and emotional components (Davis, 1980), with subscales tapping perspective-taking, fantasy, empathic concern, and personal distress. The perspective-taking subscale assesses the tendency to take another's point of view into consideration, akin to ToM. The fantasy subscale assesses the tendency to identify with fictional characters; the empathic concern subscale relates to feelings towards others; and the personal distress subscale taps the tendency to experience distress in stressful situations. Unlike ToM, objective tests have not yet been developed to assess the complex construct of empathy.

The precise relationship between ToM and empathy has yet to be ascertained. Whereas simulation theory identifies the ability to simulate the mental processes likely to be operating in another as the basis for both ToM and empathy, other theories support the dissociation of 
ToM and empathy (Blair et al., 1996). The latter arguments draw on findings on the impairment of social cognition in autistic and psychopathic populations; whereas autistic individuals lack ToM skills, they show physiological and to some extent cognitive (i.e., empathic) responses to distress cues in others. Psychopaths, in contrast, are incapable of empathizing, but show no impairment in mentalizing. Little is known about the neural correlates of this deficit (Soderstrom, 2003).

Taken together, the terms empathy, ToM, and perspective taking are often used as synonyms, both in everyday speech and in the psychological literature. All of these concepts refer to the ability to put oneself in another person's position, either mentally or emotionally (Singer, 2006). As described above, however, they rely on different neuronal circuitry. Ontogenetically, empathy seems to develop much earlier than ToM (Singer, 2006), and empathic responding requires the additional recruitment of networks involved in emotional processing (Vollm et al., 2006).

\subsubsection{Understanding Others: A Neuronal Basis?}

Social neuroscience has aimed to explain how social human experiences emerge from the neuronal structures of the brain. One major advance was the discovery of mirror neurons in the premotor cortex of the macaque (Rizzolatti, Fadiga, Gallese, \& Fogassi, 1996). Mirror neurons, a specific type of cell in the brain, are so called due to their unique quality to discharge during both the execution of a certain action and the observation of that action being executed by a conspecific (Brune \& Brune-Cohrs, 2006; Gallese \& Goldman, 1998; Rizzolatti, Fadiga, Gallese, \& Fogassi, 1996). The capacity to understand others might thus be based on mirror neurons (Gallese, 2003; Rizzolatti, Fadiga, Fogassi, \& Gallese, 2002).

In humans, social neuroscience research using techniques such as positron emission tomography (PET) and functional magnetic resonance (fMRI) (for a review see Agnew, Bhakoo, \& Puri, 2007) has produced results in line with the observations made in monkeys. The discovery of mirror neurons confirmed that a translation mechanism present in the primate brain is automatically elicited when viewing others' actions (Singer et al., 2006).

Research has not yet established whether and which mirror neurons explain the common phenomenon that humans also share complex psychological states by means of contagion (Carr, Iacoboni, Dubeau, Mazziotta, \& Lenzi, 2003). Platek and colleagues (2003) hypothesized that contagious yawning occurs as a part of a more general phenomenon known as mental state attribution (i.e., the ability to inferentially mimic the mental states of others). 
They investigated mental state attribution by presenting a non-clinical sample of respondents with short video sequences of laughing and yawning people, and examining how susceptibility to contagious yawning related to performance on a self-recognition task, Theory of Mind stories, and a measure of schizotypal personality traits. Contagious yawning was positively related to performance on faux pas Theory of Mind stories, and negatively related to schizotypal personality traits. This result suggests that contagious yawning might be related to self-awareness and empathic processing. In a later study, fMRI scans were performed while subjects watched videotaped yawns (Schürmann et al., 2005) to establish whether the mirror neuron system was involved in the process of contagious yawning. However, findings showed that the brain activation associated with seeing another person yawn seems to circumvent the essential parts of the mirror neuron system, suggesting that contagious yawning is an automatically released behavioral act and not an imitated motor pattern.

A new line of research focuses on humans' capacity for affect sharing, the capacity to automatically resonate with other people's feelings, even without being aware of doing so (Singer et al., 2006). In the literature, these effects are known as emotional contagion: the human tendency to automatically mimic and synchronize facial expressions, vocalizations, postures and movements with those of others (Hatfield, Cacioppo, \& Rapson, 1994). Emotional contagion is an implicit response in the sense that it is elicited without the requirement for any explicit, effortful perspective taking or appraisal of others' emotional states (Singer, 2006).

The discovery of mirror neurons in humans offers an explanation of how the ability to imitate the actions of others may have evolved into the capacity to simulate the mental states of others, i.e. Theory of Mind (Williams, Whiten, Suddendorf, \& Perrett, 2001). The capacity of the motor system to echo an observed action is unique to humans and, in its more developed form, is known as Theory of Mind (Agnew, Bhakoo, \& Puri, 2007).

These facets of social cognition are important requirements for functional social interaction. Little is known about how they may change after critical life events such as traumatization. Prior to the work of our research group, (Nietlisbach, Maercker, Rössler, \& Haker, 2008), there had been a dearth of empirical research on how PTSD is related to empathy and ToM. Table 1 gives an overview about the existing lines of research that link trauma aftermath or PTSD to social cognitive constructs as well as possible directions for future research. 


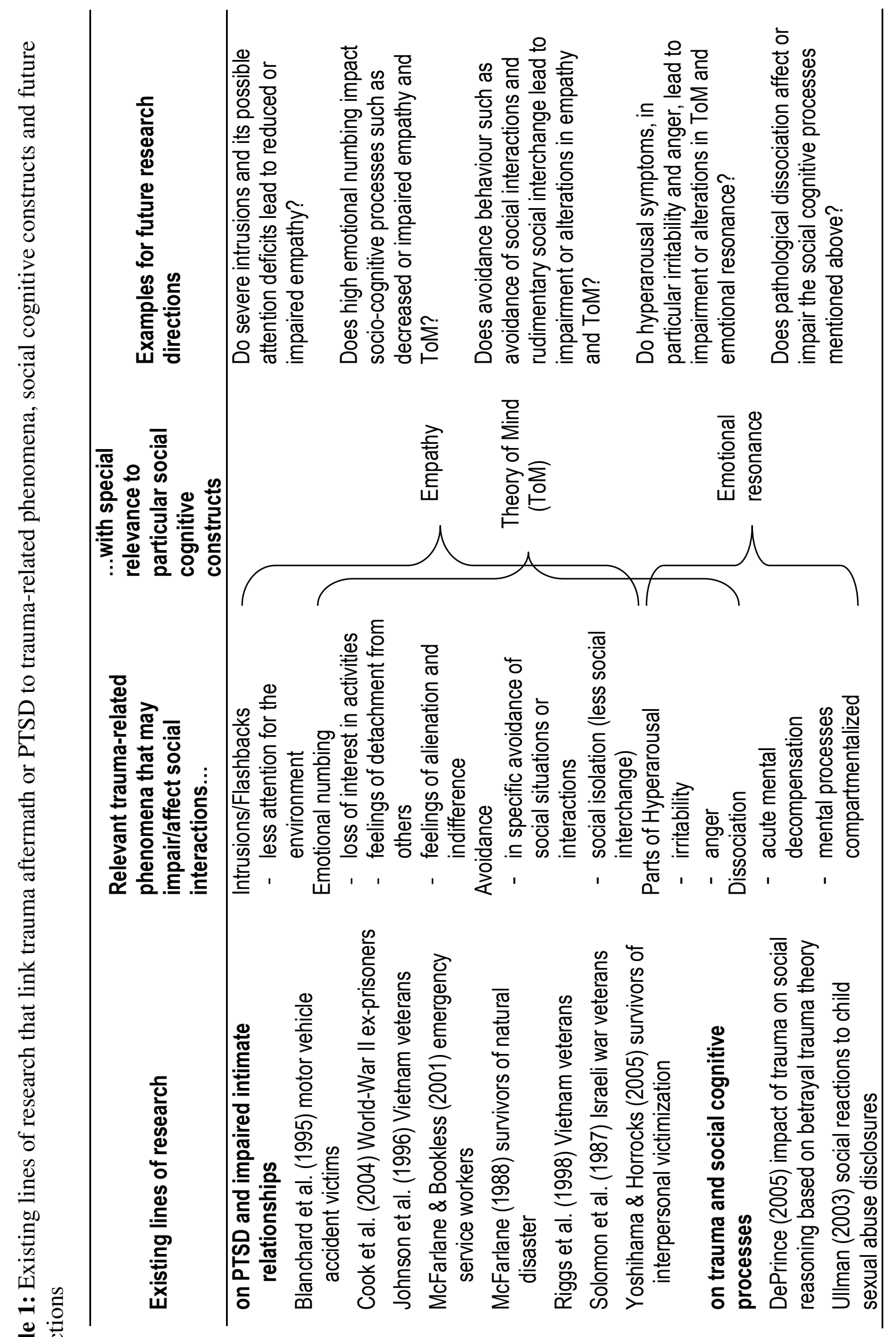




\subsubsection{Perceived Social Exclusion}

Social cognition involves not only constructive processes of understanding others, but also destructive processes, such as perceived social exclusion. Social exclusion is defined as being excluded, alone, or isolated; sometimes dislike is declared explicitly, sometimes it is not (Twenge, Baumeister, Tice, \& Stucke, 2001). Social exclusion is thus an act of ostracism (Williams, 2007). Humans are essentially social creatures, and the desire for positive social relationships is one of the most fundamental and universal of human needs (Williams, 2007). Throughout most of evolutionary history, people lived, loved, and labored in the confines of small, intimate groups. Being rejected and excluded from the group, and from all the benefits of membership, was tantamount to a death sentence. Survival thus depended on the ability to detect imminent rejection-cognitively, emotionally, and behaviorally—and to regain membership of the group (Williams, Forgas, Von Hippel, \& Zadro, 2005).

Feeling socially excluded is an unpleasant but frequent experience in everyday life situations. Williams and colleagues (2005) emphasized that every aspect of day-to-day life has the potential for some form of social exclusion, from the socially sanctioned forms of ostracism used by institutions to the more subtle signs of silence and rejection used in interpersonal relationships (e.g., withdrawal of eye contact; Williams \& Zadro, 2001). Such experiences may be an additional emotional burden for trauma victims.

Responses to social exclusion and ostracism range from decreased prosocial behavior to increased aggression (for a review see Williams, 2007). Failure to satisfy the need for belonging is known to have devastating consequences for psychological well-being (Maner, DeWall, Baumeister, \& Schaller, 2007; Williams, 2007). People who lack positive relationships often experience loneliness, guilt, jealousy, anxiety, and depression (Leary, 1990), have higher incidences of psychopathology (Bloom, White, \& Asher, 1979), and reduced immune system functioning (Cacioppo, Hawkley, \& Bernston, 2003). Recently, our research group has investigated anger and revenge in victims as a potential outcome of exclusion; for example, former East German political prisoners and crime victims (Orth, Cahill, Foa, \& Maercker, 2008; Orth, Montada, \& Maercker, 2006; Schützwohl \& Maercker, 2000). 


\subsubsection{Theoretical Approaches}

As a widespread phenomenon that is prevalent across cultures and that may in previous times have been life-threatening, social exclusion has been the subject of much research (Williams et al., 2005).

What kind of effects does social exclusion have on humans nowadays? Currently, there are three major models that attempt to explain and predict the impact and consequences of social exclusion: Williams (1997; Williams et al., 2005) has emphasized the importance of examining the impact of ostracism over time, proposing the following sequence of responses: (a) reflexive painful response to any form of ostracism, unrelieved by situational or individual difference factors; $(b)$ threats to the need for belonging, self-esteem, control, and meaningful existence, and increases in sadness and anger; $(c)$ a reflective stage that is responsive to cognitive appraisals of the situation, the sources of ostracism, the reasons for ostracism, and predisposing inclinations that reflect individual differences residing within the target of ostracism. People exposed to multiple episodes or single long-term episodes of ostracism will have a diminished ability to regulate their resources to fortify threatened needs by means of their own behavior, and feelings of helplessness, alienation, and despair will infuse their thoughts, feelings, and actions (Williams, 2007).

A second theoretical perspective focuses on how ostracism and social exclusion thwart the need to belong and how a psychological system — the social monitoring system-helps regulate optimal levels of belongingness (Gardner, Pickett, \& Knowles, 2005). When belonging is threatened, a person is motivated to attend more carefully to social cues, presumably to achieve success in subsequent social interactions.

Another theoretical framework argues that the impact of social exclusion is much like the blow of a blunt instrument, and causes a temporary state of cognitive deconstruction, similar to the affective flattening that precedes suicide attempts (Baumeister, Twenge, \& Nuss, 2002). This explanation seems particularly fitting when socially excluded individuals show no signs of mood impact (Baumeister, DeWall, Ciarocco, \& Twenge, 2005). Consistent with this explanation of cognitive impairment is the premise that social exclusion impairs individuals' ability to self-regulate, which in turn inhibits their ability to use the cognitive and motivational resources that are necessary to avoid impulsive acts. This explanation is in line with observations of anger and indiscriminant aggression that sometimes follow social exclusion (Williams, 2007). 


\subsubsection{Research Paradigms and Findings}

Social exclusion is often enforced through tactics such as the so-called "silent treatment." Silence, when communication is expected, is inextricably linked to the act of excluding somebody. Several paradigms have been used in research on social exclusion in recent decades. One of the most common manipulations of social exclusion is for respondents to be told that they will end up alone later in life or that nobody wants to pair up with them in an upcoming task (Baumeister et al., 2005; Twenge et al., 2001).

Another paradigm, developed by Williams (1997), is called ball tossing. Participants are ignored and excluded from a ball-tossing game that appears to have no connection with the experiment itself. Two confederates and one actual participant are told to wait quietly for the experimenter's return, at which point the experiment will start. One of the two confederates notices a ball and starts to toss it around. Once each person has had a chance to catch and throw the ball a few times, participants randomly assigned to the ostracism condition are no longer thrown the ball, looked at, or responded to. The two confederates continue playing for another 4 or 5 minutes. In the inclusion condition, participants continue to receive the ball approximately one third of the time (Williams, 2007; p. 430). Cyberball, an Internet version of the ball-tossing paradigm, was developed by Williams, Cheung and Choi (2000) to be more efficient (it requires no confederates).

Other investigations on social exclusion have been conducted by anthropologists, sociologists, biologists, physiologists, ethnologists, zoologists, and psychologists (Gruter \& Masters, 1986). Social psychologists, in particular, have recently become more interested in the nature of social exclusion, motivation, and the consequences of ostracism. Whereas earlier social psychological studies examined the effects of physical isolation (Schachter, 1959), more recent studies have addressed the phenomenon of ostracism. Many social psychological concepts rest on the basis that humans fear exclusion and rejection. Studies have shown that experimental episodes of social exclusion can lead to various reactions, such as depressed mood, loneliness, anxiety, feelings of helplessness, physiological arousal, or aggression in healthy people (Eisenberger, Lieberman, \& Williams, 2003; Twenge et al., 2001; Williams \& Sommer, 1997).

Recently, Twenge et al. (2007) manipulated social exclusion by telling respondents that they would end up alone later in life or that other participants had rejected them. Results showed that social exclusion led to a substantial reduction in prosocial behavior. For example, socially excluded people donated less money to a student fund, were unwilling to volunteer for further lab experiments, were less helpful after a mishap, and cooperated less with another 
student in a mixed-motive game. These effects were mediated by feelings of empathy for another person. The authors interpreted these findings to indicate that rejection temporarily interferes with emotional responses, thus impairing the capacity for empathic understanding of others.

\subsubsection{Social Exclusion and Traumatic Experiences}

Social exclusion is related to social stigmatization, another powerful phenomenon with far-reaching effects on its targets (Major \& O'Brian, 2005). Stigmatization has direct effects via mechanisms of discrimination, expectancy confirmation, and automatic stereotype activation, and indirect effects via threats to personal and social identity.

Traumatic life experiences are frequently connected with social stigmatization, particularly in cases of sexual assault. Research in social psychology has confirmed that nobody wants to be ignored. However, many traumatized people feel that their limitations and needs are ignored, and that they are no longer respected as human beings. These damaging and transboundary experiences can lead to people feeling as if they are no longer part of society, and perceiving themselves as socially isolated.

As mentioned above, social acknowledgment may be an important factor in trauma processing and trauma recovery; its absence increases the risk of PTSD (Jones, Müller, \& Maercker, 2006; Müller \& Maercker, 2006; Müller, Moergeli, \& Maercker, 2008). In other words, is seems crucial that the social environment (e.g., colleagues, neighbors, local public authorities, clergy, and the media) acknowledge the victim's unique situation and commiserate with him or her. The social environment can be seen as a replacement for society in general. It may be important for trauma survivors to experience a sort of "re-inclusion." However, social interactions and everyday life tasks can pose great difficulties for trauma survivors. Thus, the question arises as to whether trauma survivors perceive social experiences of exclusion differently from people who have not been traumatized. Empirical research has not yet examined PTSD and the impact of social exclusion on trauma processing; our research group has recently begun to investigate this area (Nietlisbach \& Maercker, 2008).

\subsection{Discussion}

The goal of this paper was to review research findings on interpersonal factors known to be associated with PTSD, and to discuss the possible effects of social cognition on these 
associations. Interpersonal factors such as social support, social acknowledgment, and quality of intimate relationships are known to be important for trauma processing and recovery. To date, research on these factors has mainly focused on the sender's perspective. In other words, research has examined whether a trauma victim receives social support and social acknowledgment, but not on individual perceptions of that support and acknowledgment. In the present article, we sought to incorporate the receiver's perspective by considering particular processes of social cognition such as the capacities for emotional resonance, empathy, and Theory of Mind.

The basic differentiation between sender- or receiver-related impairments in interpersonal relationships of victims and their social peers underpins the new Social Facilitation Model of Posttraumatic Stress Disorder by Maercker (2008a). In this model, aspects of "self", "others" and "world" interact. This interaction increases or decreases the symptoms and course of PTSD. Central to this model are symptom facilitation or recovery processes that affect the fear/dissociation network of trauma memories and the ability to integrate traumatic experiences into ones life (cf. Maercker, 2006, 2008b).

Undoubtedly, distinguishing between the capacity to emphasize and the ability for Theory of mind is no easy task because interpersonal and socio-cognitive factors are closely linked. For example, it is conceivable that the capacity to mentalize is a characteristic of well functioning intimate relationships. The better a person can predict another person's emotional state, the better he or she can react in intimate situations to improve the quality of a close relationship.

Most research in this area has been carried out in the fields of schizophrenia, autism, and psychopathy. However, trauma survivors are known to often experience severe problems in the social domain - also in context with the process of disclosure, as reviewed by Ullman (2003). The impact of social reaction - especially dysfunctional reactions such as denial or indifference - to trauma disclosure may influence processes of social cognition insofar that this may trigger more intrusions and fortify social retraction in trauma survivors. For DePrince (2005) alterations in social cognition could be a possible explanation for revictimization risk, which is related to posttraumatic dissociation. Findings from various studies show that social support and social acknowledgment play an important role in whether or not a trauma victim develops PTSD as well as in trauma processing and recovery. Research on social phenomena has also demonstrated the importance of social bonds for PTSD risk and recovery. However, the impact of these particular social cognition factors relevant to successful social interactions such as the capacity to empathize and mind-read on PTSD 
trajectories, have not yet been investigated. Why has research to date overlooked these relationships? Relative to schizophrenia and many other psychiatric disorders, PTSD is a relatively new disorder. Much research on PTSD has to date addressed symptom clusters, trauma memory, and maintaining factors. Intrusions, in particular, can limit attention deployment capacities. A trauma survivor with PTSD may thus no longer be capable of interpreting social signals in the same way as before the trauma. Fortunately, a great deal is known about factors leading to the development and maintenance of PTSD. But much remains unexplained in PTSD research. We have discussed possible changes in social cognition as one of the mechanisms-besides the known symptoms of PTSD-that may impair social relationships. Perceived social exclusion may lead to PTSD symptoms being reinforced. Taken together, changes in interpersonal factors and their interaction might be further maintaining factors for PTSD.

To conclude, studies are needed to investigate whether trauma survivors with PTSD and healthy controls differ in terms of the capacity for empathy and Theory of Mind, and in terms of emotional contagion and perceived social exclusion. Moreover, prospective studies are needed to examine the correlations and interactions between the components of social cognition presented and PTSD trajectories.

One clinical implication of these constructs might be the development of interventions designed to inform patients with PTSD about these possible changes after traumatization. By making patients aware of these possible negative consequences in the interpersonal realm, psychoeducation or interventions may serve as protective measures against further psychosocial impairments such as family or marital problems and occupational difficulties. 


\section{Are Empathic Abilities Impaired in Posttraumatic Stress Disorder?}

Nietlisbach, G., Maercker, A., Rössler, W. \& Haker, H.

Psychological Reports (submitted) 


\subsection{Abstract}

Trauma survivors with PTSD show social interaction and relationship impairments. It is hypothesized that traumatic experiences lead to known PTSD symptoms, empathic ability impairment and difficulties in sharing affective, emotional or cognitive states. A PTSD group $(\mathrm{N}=16)$ and a non-traumatized control group $(\mathrm{N}=16)$ was compared on empathic abilities: empathic resonance, Theory of Mind and causal attributions. A self-report measure of empathy and measures of non-social cognitive functions were also administered. The PTSD group showed lower empathic resonance. No clear indications of other impairments in social cognitive functions were found. The PTSD group demonstrated significantly higher personal distress. Empathic resonance impairments did not correlate with subjective severity of PTSD symptomatology. This article discusses whether impaired empathic resonance in PTSD trauma survivors is a consequence of trauma itself or a protective coping strategy. 


\subsection{Introduction}

\subsubsection{Empathy}

Empathy is defined as the ability to infer and share the emotional experiences of others (Gallese, 2003). As a vicarious experience of others' emotions, it is thought to be crucial for many forms of adaptive social interactions (Spinella, 2005). Empathy is not a unitary function, but comprises the elements of empathic resonance, emotional empathy and cognitive empathy (Blair, 2005; De Vignemont \& Singer, 2006).

Empathic resonance - the phenomenon of a person unconsciously mirroring the motor actions of another - is a basic prerequisite for human interaction. This shared representation serves as a basis for sharing the physiological and emotional states of others and is one component of empathy (Preston \& De Waal, 2002; Uddin, Iacoboni, Lange, \& Keenan, 2007). Resonance can be seen as a bottom-up contribution to emotional or cognitive empathy and is mediated by shared representations in the mirror neuron system (MNS) (Keysers \& Gazzola, 2007; Leslie, Johnson-Frey, \& Grafton, 2004; Rizzolatti \& Craighero, 2004).

The term cognitive empathy refers to the ability to understand and explain the mental states of others (i.e., Theory of Mind, ToM). ToM encompasses a range of mental abilities that are relevant to successful social interactions, including cognitions which make it possible for humans to recognize, understand, explain and communicate their own and other people's behaviors and emotions (Baron-Cohen, Tager-Flusberg, \& Cohen, 2000). ToM is defined as "the attribution of mental states, such as desires, intentions and beliefs, to others" (Frith, 1999; p.1692). A specific aspect of ToM is "mind-reading" (the terms "mind-reading" and "mentalizing" are used synonymously in the literature). ToM includes the development of mental perspective-taking as well as the recognition of more complex "faux pas" situations. A faux pas occurs when a person says something they should not have, not knowing or not realizing that they should not have said it. The inability to recognize faux pas situations may be detrimental to relationships.

Attribution of the causes or effects of others' behaviors can be seen as another cognitive form of empathy that is widespread in daily life. This can be seen as a general coping strategy designed to make the social world more predictable and controllable (Kelley, 1967). According to Kelley's (1967) attribution theory, one can attribute the cause of a situation to the subject carrying out an action (internal attribution), to the object at which the action is directed (external attribution) or to circumstances accompanying a situation. Individuals are 
assumed to make causal attributions by identifying covariations or correlations and interpreting these as causal relationships.

\subsubsection{Empathic Abilities and PTSD}

Reduced empathic abilities can have multiple effects on relationships. It is well known that interactions between trauma survivors with posttraumatic stress disorder (PTSD) and close friends and family, as well as survivors' acceptance of social support, play a crucial role in the processing of the traumatic experience (Maercker \& Müller, 2004; Schnurr, Lunney, \& Sengupta, 2004). A meta-analysis examining the risk factors related to PTSD identified a lack of social support as the strongest predictor for maintenance of PTSD (Brewin, Andrews, \& Valentine, 2000). Scarpa and colleagues (Scarpa, Haden, \& Hurley, 2006) found that low perceived social support from family and friends predicted significantly higher PTSD scores. In addition, social acknowledgment has also been shown to affect the victim's mental state, thus influencing the further processing of the traumatic experience (Jones, Müller, \& Maercker, 2006). These findings highlight the important potential benefits of exchange with others and of social support and understanding for trauma victims.

However, trauma victims with PTSD often show impairments in interpersonal functioning and difficulties interacting with intimate social partners that may dilute or nullify these benefits. Relationships with close network partners are often especially difficult and conflicted after the traumatic event (Cook, Riggs, Thompson, Coyne, \& Sheikh, 2004; Riggs, Byrne, Weathers, \& Litz, 1998). It has been suggested that the capacity to interact with social partners after a traumatic experience may be reduced due to an impaired perception of the feelings and experiences of others (Maercker, Schützwohl, \& Solomon, 1999). This phenomenon may be a symptom or the cause of the psychosocial impairments frequently present in PTSD. We are not aware of any previous studies that have investigated the relationship between psychosocial dysfunctions and empathic abilities in PTSD.

\subsubsection{The Present Study}

The aim of the present study was to identify group differences in the empathic abilities of individuals with PTSD and non-traumatized controls. To this end, we administered objective assessments of empathy in terms of empathic resonance (contagion) and social cognitive functions (ToM, attributional style), as well as a self-report measure of empathy 
(Interpersonal Reactivity Index) and measures of non-social cognitive functions (Stroop test, verbal and figurative fluency tests).

Working on the assumption that changes in empathic abilities are one of several mechanisms that may impair the maintenance of close social relationships in individuals with PTSD, we expected trauma survivors with PTSD to show impairment in empathic abilities (i.e., resonance and/or social cognitive functions) relative to non-traumatized controls and to have greater difficulty recognizing social signals (i.e., to show impaired response appropriateness to social signals). Accordingly, we addressed the following research questions:

- What are the group differences between PTSD and control samples in objective and subjective empathic abilities and other relevant measures?

- How does the severity of PTSD correlate with impairments in empathic abilities?

\subsection{Materials and Methodology}

\subsubsection{Participants}

Two groups were investigated: a non-treatment seeking, untreated PTSD group $(\mathrm{N}=16)$ and a non-traumatized control group $(\mathrm{N}=16)$. The groups were matched for sex, age and years of education. The PTSD group was recruited through advertisements in newspapers, on homepages or through correspondence with counseling centers. Non-traumatized controls were either associates of the investigators or students. Age ranged from 20 to 71 years in the PTSD group $(M=43.69, S D=14.80)$ and from 21 to 63 years in the control group $(M=$ 42.31, $\mathrm{SD}=11.24 ; \mathrm{t}=-.29, \mathrm{df}=30, p=.76)$. In both groups, exactly half $(50 \%)$ of the participants were female. Seven participants in the PTSD group met the criteria for a diagnosis of full PTSD and nine were subsyndromal (for clinical assessments, see below). Thirteen had experienced a man-made trauma (e.g., sexual assault) and three had survived an accidental trauma or natural catastrophe (e.g., tsunami). The mean time since trauma in the PTSD group was 4.0 years ( $\mathrm{SD}=4.08$ years, range: $1-18$ years).

\subsubsection{Measures}

\subsubsection{Assessment of PTSD}

PTSD was assessed by clinical ratings (SCID) and a self-report questionnaire (IES-R). 
Structured Clinical Interview for DSM-IV (SCID; First, Gibbon, Spitzer, \& Williams, 1996)

The SCID for SSM-IV was used to confirm diagnoses of PTSD or subsyndromal PTSD. All DSM-IV criteria had to be met for a diagnosis of full PTSD. Based on Blanchard and colleagues' definition of subsyndromal PTSD (1996; Hickling \& Blanchard, 1992), participants were classified as subsyndromal if they reported the minimum number of symptoms for the reexperiencing criterion, and met either the avoidance criterion or the hyperarousal criterion.

Impact of Event Scale - Revised (IES-R; Weiss \& Marmar, 1996)

This self-report scale measures the subjective impact of the 22 PTSD symptoms on a 4point Likert scale. The three subscales of intrusion, avoidance and hyperarousal measure typical forms of reactions to and symptoms of extremely distressing events. The intrusion subscale comprises seven items ( $\alpha=.90$; values: $0-35)$, the avoidance subscale eight items ( $\alpha$ $=.79$; values: $0-40)$ and the hyperarousal subscale seven items $(\alpha=.90$; values: $0-35)$. Participants were requested to base their answers on their most important traumatic experience and their symptoms during the last 7 days.

In addition, we analyzed the association between time since trauma and scores on the other measures.

\subsubsection{Objective Tests of Resonance and Social Cognitive Functions}

\subsubsection{Empathic Resonance}

Participants' susceptibility to contagion (laughing and yawning) was measured by presenting them with 24 video sequences of yawning, laughing or neutral facial expressions. The video sequences were recorded using volunteers. Participants were asked to relax and to imagine that they were sitting opposite another person (i.e., the person being shown on the screen) in a waiting room, and that they were aware of but not in verbal contact with the other person. Participants were asked not to suppress any effect the other person's behavior may have on them. After each sequence, they were asked to answer two distracter questions presented on the computer screen ("How comfortable did you feel while viewing the sequence?" and "How likeable did you find the person in the sequence?"). Responses to both questions were given on a 5-point Likert scale ranging from not at all to very. Participants' faces were video-recorded as they watched the video sequences. The recordings were rated 
for contagion of yawning and contagion of laughing. A similar setup has been used by Platek and colleagues (2003).

\subsubsection{Reading the Mind in the Eyes Test - Revised Version (RMET; Mind- Reading) (Baron-Cohen, Wheelwright, Hill, Raste, \& Plumb, 2001).}

The RMET is a four-choice task assessing cognitive empathy in terms of mind-reading. Participants were presented with a series of 36 photographs of male and female facial eye regions and instructed to choose one of four words that best described what the person in the picture was thinking or feeling. This task is considered an advanced ToM test as participants are required to put themselves in the mind of the person pictured and to attribute a relevant mental state to them. The task was self-paced, and the test scored by totaling the number of items (36 photographs in total) correctly identified by the participant.

\subsubsection{Faux Pas Test (Baron-Cohen, O'Riordan, Stone, Jones, \& Plaisted, 1999)}

In an approach based on the faux pas story paradigm developed by Baron-Cohen et al. (1999), participants were shown videos of 10 faux pas stories (each lasting about 1 minute) on a computer. The video sequences were produced using professional actors. After each story, participants were asked to answer the following questions:

1. A control question that did not relate to the faux pas (e.g., "Who baked the cake?")

2. "Was there a faux pas in the story?"

3. "Who committed a faux pas?"

4. A question about the mental state of the person who committed the faux pas.

This assessment was scored by awarding 1 point for each correctly identified faux pas (i.e., providing the correct answer for each of the four questions). The maximum score was 10.

\subsubsection{Attribution Model}

Drawing on Kelley's (1967) attribution theory, we assessed attributional style in social situations using the approach developed by Rössler and Lackus (1986). In this approach 58 descriptions of social situations were presented on a screen together with additional information about the given situation. Individuals were asked to make causal attributions on the basis of three given choices. The presentation of additional information about consensus (concerning the subject), consistency (concerning the object) or distinctiveness (concerning 
the situation), allows for "correct" causal attributions on the basis of three choices: a) attribution to the acting subject in a social situation (internal attribution), b) attribution to the object of the action (external attribution) and c) attribution to circumstances unrelated to the action/the situation (circumstantial attribution). Theoretically no false attributions can be made. Kelly's attribution theory is a normative model that predicts an optimal answer. The attributional style was computed as the number of "incorrect" internal, external and circumstantial attributions respectively.

\subsubsection{Subjective Measure of Empathic Abilities}

\subsubsection{Interpersonal Reactivity Index (IRI; Davis, 1983)}

The IRI is a self-report measure of empathy. It comprises 28 items (each rated on a 5point scale ranging from 0 this is not at all true for me to 4 this is absolutely true for me) and four subscales: (1) "Fantasy Scale" (FS), which measures the tendency to fantasize about fictional characters; (2) "Empathic Concern" (EC), which specifically addresses the respondent's capacity for concerned and compassionate feelings for others; (3) "Perspective Taking" (PT), which concerns mentalizing abilities; and (4) "Personal Distress" (PD), which records self-oriented responses to difficult situations of others.

\subsubsection{Executive Functions}

The following tests were administered to identify and control for deficits in executive functions that may affect the assessment of empathic abilities.

\subsubsection{Verbal Fluency (Aschenbrenner, Tucha, \& Lange, 2000)}

Following Regard, Strauss, and Knapp (1982), we assessed phonemic verbal fluency by asking participants to produce as many different words beginning with the letter " $\mathrm{S}$ " as possible in 3 minutes. Participants were instructed not to produce proper nouns or to repeat words. The total number of words produced was recorded. 


\subsubsection{Figural Fluency (Regard, Strauss, \& Knapp, 1982)}

Nonverbal fluency was assessed by means of the Five-Point Test (Regard, Strauss, \& Knapp, 1982). Test items are presented on a sheet partitioned into rectangles. Five symmetrically arranged black dots are printed in each rectangle. Participants were asked to produce as many different figures as possible in 3 minutes by connecting the dots in each rectangle with straight lines. The total number of figures produced was scored.

\subsubsection{Stroop Test (Jensen \& Rohwer, 1966; Stroop, 1935)}

Cognitive flexibility was assessed using the Stroop Test (Stroop, 1935) in the list version described by Perret (1974). The test consists of three cards, each containing six rows of four items (1974; Strauss, Sherman, \& Spreen, 2006). On the first card, dots are printed in different colors, with each color appearing once in each row. On the second card, the dots are replaced by common words, and on the third card, the common words are replaced by color names arranged in such a way that the print color never corresponds to the color name. The three cards are always presented in the above sequence. Participants were instructed to state the color (of the dots, the words or the color names) as quickly as possible. Response time and number of errors was recorded for each section.

\subsubsection{Procedure}

After they gave written informed consent, participants were assessed for PTSD (SKID, IES-R). They were then invited to the laboratory, where the following measures were administered (either in paper form or on the computer): Reading the Mind in the Eyes Test (RMET), Faux Pas Test (Theory of Mind), Resonance Test and Interpersonal Reactivity Index Questionnaire. Participants were then debriefed and paid CHF 50. The study had previously been approved by the ethical committee of Zurich.

\subsubsection{Data Analysis}

Statistical analyses were performed using the SPSS 15.0 statistical software for Windows. Because some of our main outcome variables were non-normally distributed (Kolmogorov-Smirnov test: $p<0.05$ ), the more conservative nonparametric Mann-Whitney test was used to compare groups. To maintain consistency, the Mann-Whitney test was 
applied throughout. Bivariate Pearson correlations were computed to asses how severity of PTSD related to empathic abilities and non-social cognitive functions.

\subsection{Results}

\subsubsection{PTSD Characteristics}

Seven participants in the PTSD group met the criteria for a diagnosis of full PTSD; nine were classified as subsyndromal (as defined in Blanchard et al., 1996). The PTSD sample scored a mean of $20.56(\mathrm{SD}=7.94)$ on the intrusion subscale, $23.38(\mathrm{SD}=7.67)$ on the hyperarousal subscale and $19.63(\mathrm{SD}=9.61)$ on the avoidance subscale of the IES-R selfreport questionnaire.

Time since trauma showed a significant positive correlation only with scores in the Reading the Mind in the Eyes Test $(\mathrm{r}=.52 ; p<0.05)$ and not with the other objective tests.

Table 2: Sample Description

\begin{tabular}{lll}
\hline & PTSD group & Control group \\
\hline $\mathbf{N}$ & 16 & 16 \\
Female gender & 8 & 8 \\
Age & $\mathrm{M}=43.69(\mathrm{SD}=14.80)$ & $\mathrm{M}=42.31(\mathrm{SD}=11.24)$ \\
Education in years & $\mathrm{M}=14.44(\mathrm{SD}=3.03)$ & $\mathrm{M}=14.31(\mathrm{SD}=2.24)$ \\
& Accidental: 3 & \\
Trauma type & Man-made: 13 & N/A \\
\hline
\end{tabular}

\subsubsection{Group Differences}

Table 3 presents our findings on group differences. One main result was that the PTSD group demonstrated significantly less contagion of laughing and yawing than the controls in the objective resonance test. 
There was no significant group difference in performance on the Reading the Mind in the Eyes Test $(p=.14){ }^{1}$

No significant group differences were found for the Faux Pas Test (see table 3). Regarding causal attributions in social situations, individuals in the PTSD group made significantly more external attributions than controls (table 3).

Regarding the subjective self-report of empathic abilities as assessed by the Interpersonal Reactivity Index, the PTSD group scored significantly higher than the control group on the Personal Distress subscale.

\footnotetext{
${ }^{1}$ Because the RMET is normally distributed, a parametric analysis was also conducted. RMET (KolmogorovSmirnov: $p=0.41)$ tested with analysis of variance (ANOVA) demonstrated a tendency $(\mathrm{F}=3.06, \mathrm{df}=1$, $p=0.09$ ) (if controlled for time since trauma with: $\mathrm{F}=4.52, \mathrm{df}=1, p=0.05$ ) regarding the group differences.
} 
Table 3: Group Differences in Empathic Abilities (Objective and Self-Reported) and Executive Functioning

\begin{tabular}{|c|c|c|c|c|c|c|}
\hline & \multicolumn{2}{|c|}{ PTSD group } & \multicolumn{2}{|c|}{ Control group } & \multicolumn{2}{|l|}{ Mann-Whitney } \\
\hline & M & SD & M & SD & $U$ & $p$ value \\
\hline \multicolumn{7}{|l|}{ Empathic Resonance } \\
\hline Yawning & 0.56 & 1.31 & 3.31 & 3.13 & 52.5 & $<0.01$ \\
\hline Laughing & 1.75 & 2.17 & 4.94 & 2.48 & 37.0 & $<0.001$ \\
\hline Reading the Mind in the Eyes Test & 24.19 & 4.69 & 26.56 & 2.73 & 89.50 & .14 \\
\hline Faux Pas Test & 7.81 & 0.91 & 7.31 & 2.18 & 115.50 & .63 \\
\hline \multicolumn{7}{|l|}{ Attributional Style } \\
\hline Internal attributions & 5.13 & 2.77 & 7.31 & 8.04 & 116.5 & .66. \\
\hline External attributions & 11.00 & 5.78 & 6.81 & 3.56 & 68.50 & $<0.05$ \\
\hline Circumstantial attributions & 4.00 & 3.52 & 3.38 & 2.58 & 123.50 & .86 \\
\hline \multicolumn{7}{|l|}{ Interpersonal Reactivity Index } \\
\hline Empathic Concern & 20.50 & 4.63 & 20.69 & 3.66 & 128.0 & 1.0 \\
\hline Fantasy Scale & 16.94 & 6.00 & 16.31 & 5.39 & 121.5 & .80 \\
\hline Personal Distress & 17.63 & 4.10 & 12.38 & 4.91 & 59.5 & $<0.01$ \\
\hline Perspective Taking & 14.94 & 3.77 & 17.38 & 3.77 & 82.5 & .09 \\
\hline Verbal Fluency Test & 30.12 & 13.17 & 34.31 & 11.03 & 98.5 & .26 \\
\hline Figural Fluency Test & 33.93 & 11.81 & 37.93 & 11.87 & 109.5 & .48 \\
\hline Stroop Test & 1.95 & .84 & 1.79 & 0.29 & 126.0 & .94 \\
\hline
\end{tabular}


Our assessments of executive functions as non-social cognitive abilities found that there were no group differences and that there was no significant correlation between executive functioning and empathic abilities. Therefore, it can be assumed that the differences in resonance identified were not caused by differences in executive functioning.

\subsubsection{Associations between Empathic Abilities and Psychopathology}

No significant correlations were found between empathic abilities (resonance and social cognition) and the severity of PTSD (IES-R subscales).

Table 4: Associations between Empathic Abilities and Psychopathology

IES-R: Intrusion $\quad$ IES-R: Hyperarousal IES-R: Avoidance

Empathic Resonance

$\begin{array}{lccc}\text { Yawning } & \mathrm{r}=-.19 & \mathrm{r}=-.35 & \mathrm{r}=.27 \\ \text { Laughing } & \mathrm{r}=-.23 & \mathrm{r}=.29 & \mathrm{r}=.19 \\ \text { Reading the Mind in } & \mathrm{r}=.33 & \mathrm{r}=.04 & \mathrm{r}=.01 \\ \begin{array}{l}\text { Eyes Test } \\ \text { ux Pas Test }\end{array} & \mathrm{r}=-.41 & \mathrm{r}=-.16 & \mathrm{r}=-.23\end{array}$

Attributional Style

$\begin{array}{lccc}\begin{array}{l}\text { Internal } \\ \text { attributions }\end{array} & \mathrm{r}=-.05 & \mathrm{r}=.06 & \mathrm{r}=.21 \\ \begin{array}{l}\text { External } \\ \text { attributions }\end{array} & \mathrm{r}=.14 & \mathrm{r}=-.09 & \mathrm{r}=.30 \\ \begin{array}{l}\text { Circumstantial } \\ \text { attributions }\end{array} & \mathrm{r}=.10 & \mathrm{r}=-.01 & \mathrm{r}=.40\end{array}$

Note. r-values: Spearman's rho; no significant correlations. Likewise, no significant correlations were found using Pearson's r statistic. 


\subsection{Discussion}

The aim of the present research was to compare empathic abilities in individuals with PTSD and in non-traumatized controls. We hypothesized that the PTSD group would show impaired empathic abilities.

Our main findings can be summarized as follows. First, participants with PTSD showed highly reduced empathic contagion of both yawning and laughing relative to non-traumatized controls. This impaired resonance was not associated with PTSD severity. Second, no major group differences were found in the cognitive component of empathy (i.e., in the tests of social cognitive function). Findings for the RMET were somewhat borderline: there was a trend to impaired mind-reading in individuals with PTSD; based on non-parametric testing, however, the difference was not statistically significant. This was the only result showing a positive correlation with time since trauma; the relationship decreased with distance to the trauma. The more complex, but everyday, cognitive empathic ability to recognize a faux pas situation seemed to be unimpaired in this study.

In sum, we found a clear pattern of dissociation in the empathic abilities of individuals with PTSD, with marked impairment in the non-reflective, bottom-up ability to resonate, but no significant impairment in reflective, cognitive components, such as mind-reading or faux pas recognition.

In terms of self-reported empathic abilities (IRI), individuals with PTSD and controls reported the same levels of cognitive abilities ("fantasy" and "perspective taking"), but individuals with PTSD reported significantly more personal distress in the sense of selforiented responses to difficult situations of others. The latter can be seen as an equivalent of stressful contagion.

Our findings of unimpaired empathic concern combined with increased personal distress in the PTSD group suggests that the non-reflective, bottom-up perception of social-emotional content may be intact and that the reduction of observable resonance may be the result of topdown suppression.

Findings on the attributional style indicated that PTSD individuals are significantly more likely to make external attributions than healthy controls. This result is in line with previous findings, showing that individuals with PTSD make more external attributions than controls. This could mean that they tend to see the locus of control in their counterpart and not in themselves or in unrelated circumstances (Ginzburg, Solomon, Dekel, \& Neria, 2003; Mikulincer \& Solomon, 1988; Regehr, Cadell, \& Jansen, 1999; Rotter, 1966). It is well- 
known that an external locus of control can be detrimental to mental health and that people with an internal locus of control are less likely to suffer from chronic depression (Abramson, Seligman, \& Teasdale, 1978). A study with women who had been sexually abused in childhood found that those with an external locus of control reported extremely elevated levels of distress, whereas those with an internal locus of control reported lower levels of distress (Porter \& Long, 1999). The elevated external attributional style in our PTSD group compared to the controls may reflect their proneness to the disorder rather than being solely a consequence of the trauma.

Reduced empathic abilities have been reported for other diagnostic groups, mainly in the context of schizophrenia and autism. Both the cognitive empathic component and resonance are known to be impaired in autism and Asperger syndrome (Baron-Cohen, O'Riordan, Stone, Jones, \& Plaisted, 1999; Baron-Cohen, Wheelwright, Hill, Raste, \& Plumb, 2001; Iacoboni \& Dapretto, 2006; Senju et al., 2007). Social cognitive deficits are common in schizophrenia (Penn, Corrigan, Bentall, Racenstein, \& Newman, 1997); a reduced ability to resonate has also been found in this patient group (Haker \& Rössler, submitted). The same results on the self-report (IRI) have been reported for individuals with schizophrenia as found in our PTSD sample: increased personal distress, but no difference relative to controls in empathic concern or the cognitive subscales (Haker \& Rössler, submitted; Montag, Heinz, Kunz, \& Gallinat, 2007). In contrast, individuals with Asperger syndrome have been found to report lower cognitive abilities but normal empathic concern and increased personal distress (Rogers, Dziobek, Hassenstab, Wolf, \& Convit, 2007).

The impairments identified seem to be independent of the subjective severity of PTSD symptomatology. This finding may imply that different levels of PTSD symptom load (severe or moderate PTSD) in the sample do not interact with the extent of impaired empathic response. In general, as we have no information about the premorbid empathic abilities of the participants with PTSD, we cannot conclude that their low levels of empathic resonance are (solely) a reaction to the trauma. However, our findings do seem to reflect a fundamental adjustment of non-reflective responses to contagious social information, independently of time since trauma and subjective symptom load. Suppression of contagion might be an unconscious coping strategy of the aroused system, preventing the individual from being overwhelmed by the stressful experiences of others.

The findings of the present study have several limitations: First, regarding the sampling it must be noted that we had only seven participants fulfilling the criteria for full PTSD diagnosis and nine participants were subsyndromal. Although the subsyndromal rate is high, 
this does not imply that the sample is not affected. This has been previously suggested by Schützwohl and Maercker (1999) who have shown that the subsyndromal PTSD group has a higher level of predisposition to avoidance, intrusion and hyperarousal as assessed by the Impact of Event Scale. This has been supported by our study in terms of high scores of the PTSD group on the Impact of Event Scale. Another sampling problem is that sample size was small and thus limits the generalizability of research: therefore a replication of the present research with a larger sample is warranted. Second, because we used the methodological paradigm of a cross-sectional or one-shot examination, it is not possible to predict whether our findings are context-dependent or context-independent. Repeated testing would be required to evaluate effects over time. Third, restricted study resources did not allow to control for comorbidity in the PTSD group.

\subsection{Conclusion}

Within the multicomponent concept of empathy, traumatic stress seems to have a specific impact on the bottom-up input of social information and its non-reflected output which is observable as resonance. Bottom-up contagious information is processed by the MNS via the insula-amygdala connection, which is directly linked to the limbic nervous system and can elicits rapid stress responses (Augustine, 1996; Iacoboni \& Dapretto, 2006). This seems to make this component of empathy especially vulnerable to conditions of altered stress reactions.

One clinical implication of these findings might be the development of interventions designed to inform patients about these possible changes after traumatization. By making patients aware of these possible negative consequences in the interpersonal realm, psychoeducation or interventions may serve as protective measures against further psychosocial impairments (e.g., family or marital problems, occupational difficulties).

Cognitive-behavioral techniques can be used to treat stressful response to social situations with subsequent suppression of emotional sharing and avoidance of close social contacts. 


\title{
4. Effects of Social Exclusion in Trauma Survivors with PTSD
}

\author{
Nietlisbach, G. \& Maercker, A.
}

Psychological Trauma: Theory, Research, Practice, and Policy (submitted) 


\subsection{Abstract}

Trauma survivors with posttraumatic stress disorder (PTSD) often report social stigmatization and isolation. Williams (2001) provided an experimental paradigm to assess behavioral effects of social exclusion. This paradigm (face-to-face version) has been applied in a $2 \times 2$ group x experimental condition design. Participants of the PTSD group $(\mathrm{N}=16)$ and the nontraumatized control group $(\mathrm{N}=25)$ were randomly assigned to an exclusion or inclusion condition. The results showed expected main effects for the majority of outcome measures (belonging and meaningful existence, well being, psychopathology) and interaction effects were found mainly for psychopathological assessments. The research concludes that a general assumption of elevated levels of self-perceived social exclusion in PTSD patients has to be considered in terms of differentiated psychopathological effects of exclusion. 


\subsection{Introduction}

For the last decade, research on interpersonal acceptance and exclusion has proliferated. Several experimental paradigms have evolved which vary in efficiency, domain specificity and strength (e.g., Williams, 2007). Williams (2001; Williams \& Sommer, 1997) proposed an experimental manipulation to induce self-perceived feelings of social exclusion by introducing a ball tossing game in which participants are led to believe that they are accepted by other players as a playing partner in the game. In reality the "other" players are confidants of the experimenter and, during the course of the game, begin to exclude the participant from the game. Previous research has shown such manipulation to have various psychological effects, in particular, what has become known as ostracism (Gruter \& Masters, 1986; Kurzban \& Leary, 2001; Twenge, Baumeister, Tice, \& Stucke, 2001). Williams (2001) provided a needs threat model to measure main effects in ostracism. This model includes (threats to the) need of belonging, self-esteem, control and personal meaning ("meaningful existence"). Recently, the application of the ball-tossing paradigm in research has been adapted to no longer use a face-to-face version. Rather a virtual reality cartoon version has become the accepted method as it is easier to implement ('Cyberball', see Williams \& Jarvis, 2006; Zadro, Williams, \& Richardson, 2004).

Individuals with PTSD often report various forms and feelings of psychosocial stigmatization (Bolton, Litz, Glenn, Orsillo, \& Roemer, 2002; Borja, Callahan, \& Long, 2006; Kallstrom-Fuqua, Weston, \& Marshall, 2004). Previous research by the authors (see Maercker, 2008a; Maercker, 2008b; Nietlisbach \& Maercker, in press) has discussed how features of posttraumatic symptomatology (e.g., feeling alienated, chronic hyperarousal) and interpersonal factors (e.g., social rejection, so-called compassion fatigue towards trauma survivors) may lead to an increase and generalization of social exclusion experiences in people with PTSD. In the context of PTSD, such experiences may be an additional emotional burden for trauma victims. On the other hand, social acknowledgment as a victim or survivor has been found to be a recovery factor for PTSD (Maercker \& Müller, 2004; Müller, Moergeli, \& Maercker, 2008).

The present research aims to apply the behavioral social exclusion paradigm to investigate the phenomenon of social exclusion for the first time more closely in traumatized individuals. Since the ball tossing game has shown large effects on healthy people (Williams, 2007), small additional effects were expected for traumatized people. In extension to Williams and colleagues (Post Game Questionnaire; 1997; Williams \& Sommer, 1997) main 
outcome measures, a pre-post experiment change measure of emotional well being and a psychopathology scale (Brief Symptom Inventory; Derogatis, 1992) were included.

\subsection{Methods}

\subsubsection{Participants}

In a $2 \times 2$ (group $\mathrm{x}$ experimental condition) design two groups were investigated: a nontreatment seeking, untreated PTSD group $(\mathrm{N}=16)$ and a non-traumatized control group $(\mathrm{N}=$ 25). The groups were matched for sex, age and years of education. Due to limited recruiting success of participants with PTSD, the sample size of this group was smaller $(\mathrm{N}=16)$. Ages ranged from 21 to 68 years $(\mathrm{M}=37.32, \mathrm{SD}=14.44)$. In the control group, $72 \%$ of participants were female and years of education ranged from 10 to 20 years $(\mathrm{M}=14.28, \mathrm{SD}=$ 2.95). The PTSD group was recruited through newspaper advertisements, the internet and correspondence with counseling centers. Ages ranged from 22 to 57 years $(\mathrm{M}=36.00, \mathrm{SD}=$ 10.68), with no significant difference to the non-trauma group $(\mathrm{t}=.31, \mathrm{df}=39, p=.76) .81 \%$ were female, with no difference to the non-trauma group $(\mathrm{t}=.66 \mathrm{df}=39, p=.51)$. Years of education ranged from 8 to 16 years $(\mathrm{M}=12.53, \mathrm{SD}=1.91)$, indicating a slight group difference $(\mathrm{t}=2.09$, df $=39, p=.04)$. Thirteen participants had experienced a man-made trauma (e.g., sexual assault) and three had survived an accidental trauma or natural catastrophe (e.g. tsunami). The mean time since the trauma in the PTSD group was 9.4 years (SD $=7.17$ years, range: $1-27$ years). Ten participants in the PTSD group met the criteria for a diagnosis of full PTSD and six were subsyndromal (as defined by Blanchard et al., 1996). Severity scores on the IES-R intrusion scale (see below) were $M=21.88$ ( $\mathrm{SD}=8.22), \mathrm{M}=$ $22.44(\mathrm{SD}=5.29)$ on the hyperarousal scale and $\mathrm{M}=20.13(\mathrm{SD}=9.25)$ on the avoidance scale.

\subsubsection{Assessments}

\subsubsection{PTSD and related assessments}

The Structured Clinical Interview for DSM-IV (SCID; First, Gibbon, Spitzer, \& Williams, 1996) was used to diagnose subsyndromal or full PTSD. All the PTSD DSM-IV criteria had to be meet for a diagnosis of full PTSD to be given. Subsyndromal PTSD was assigned according to Blanchard's definition (1996; Hickling \& Blanchard, 1992). According 
to Blanchard (1996) participants were classified as subsyndromal if they reported the minimum number of symptoms for the re-experiencing criterion and met either the avoidance criterion or the hyperarousal criterion.

The Impact of Event Scale - Revised (IES-R; Weiss \& Marmar, 1996) is a widely used self-report measure of posttraumatic stress and was used to determine the subjective impact of PTSD symptoms. Its three subscales (intrusion, avoidance and hyperarousal) were assessed on a 4-point Likert scale. The intrusion subscale comprised seven items ( $\alpha=.90$; values: 0 $35)$, the avoidance subscale eight items ( $\alpha=.79$; values: $0-40)$ and the hyperarousal subscale seven items ( $\alpha=.90$; values: $0-35$ ). Participants were requested to base their answers on their most important traumatic experience and symptoms during the last 7 days. Psychometric features regarding test-retest reliability were satisfactory.

The Social Acknowledgment as Victim or Survivor Questionnaire (SAQ; Maercker \& Müller, 2004) assessed the degree to which affected people feel appreciated and supported by their social network following a traumatic event. The scale consists of the following three subscales: recognition ( 6 items; $\alpha=0.79$ ), general disapproval ( 5 items; $\alpha=0.82$ ) and family disapproval (5 items; 0.78). The answers are rated on a six-point Likert scale ranging from denial (0) to agreement (5). Psychometric properties were satisfactory with test-retest reliability ranging from 0.74 to 0.85 .

Life satisfaction was measured by the Satisfaction with Life Scale (Diener, Emmons, Larsen, \& Griffin, 1985). This self-rating questionnaire assessed global life satisfaction using 5 items. Each item was rated on a scale from 1 (do not agree at all) to 7 (completely agree). Psychometric features demonstrated high internal consistency $(\alpha=0.88)$ and a satisfactory test-retest reliability $(0.74)$.

\subsubsection{Outcome Measures}

The Post Game Questionnaire (also known as "Threat to need Scale; Williams, 1997) assessed the extent of belonging, self-esteem, control and meaningful existence on four scales. Answers were rated on a 5-point Likert scale ranging from not at all (1) to completely (5). In the current sample, internal consistency was $\alpha=.77$ for belonging, $\alpha=.81$ for selfesteem and $\alpha=.84$ for meaningful existence. These scales were accompanied by two manipulation check items to control for experimental effect (Williams, 1997). 
Emotional well-being (Visual analogue scale) assessed changes in current well-being before and after the experimental manipulation using a visual analogue scale. Participants rated their current emotional well-being on a continuum between very negative and very positive. Two differences' scores were derived: $\Delta_{\text {pre-post }}$ well being and $\Delta_{\text {pre-follow up well-being. }}$ Follow up was assessed immediately before the debrief (approximately 25 minutes after the social manipulation).

The Brief Symptom Inventory (BSI; Derogatis, 1992) is a self-report questionnaire which comprises 53 items and represents the brief form of the Symptom Check List-90Revised. The inventory measured psychological symptoms and distress in terms of nine symptom dimensions and global indices. The Global Severity Index (GSI) was used as a global index and five of the nine subscales relevant to PTSD (depression, anxiety, hostility, paranoid ideation and psychoticism) were employed. Each item was rated on a 5-point Likert Scale $(0=$ not at all; $4=$ extremely). Psychometric properties for the subscales showed good internal consistency $(.71-.85)$ and satisfactory test-retest reliability $(.68-.91)$.

\subsubsection{Procedure}

\subsubsection{Design and Experimental Manipulation}

Williams and Sommer (1997) developed a face-to-face ball tossing paradigm in which participants are ignored and excluded within the context of a ball tossing game (Warburton, Williams, \& Cairns, 2006; Williams et al., 2002). In the current research, the group $x$ condition design distinguished between the exclusion and inclusion condition. In the exclusion condition, participants began to interact with the confidants (see below) by playing ball for one and a half minutes, but where subsequently excluded, for three and a half minutes, from the ball tossing game. In the inclusion condition participants participated in the ball tossing game for the entire duration of the game. A cover story was set up in which participants had to wait in a pre-arranged waiting room. The ball tossing experiment took place in the waiting room and the entire experiment lasted 5 minutes for both conditions.

\subsubsection{Timeline}

The study comprised 4 steps: pre-assessment/instruction, experiment, immediate postassessment and follow-up assessment/debrief. After written informed consent was obtained, a 
diagnosis for PTSD (SKID, IES-R) was made and other psychopathological measures were conducted. In the pre-assessment phase, the visual analogue scale on emotional well-being and two socio-cognitive tasks (which will be reported elsewhere) (Haeny, Nietlisbach, \& Maercker, 2009) were implemented as part of the cover story. At this point in time the assessments were stopped, participants were asked to return to the waiting room and were instructed not to talk to each other to prevent information exchange. They were informed that as soon as the investigator was ready, they would return to the laboratory. The actual experiment took place while participants were waiting in the waiting room, where two confederates - one elderly (recruited from senior classes at the University) and one young person (usually a student) - were already sitting in the waiting room. The experiment was set up so that one of the confederates noticed a ball in an open box and began to toss it around. In the inclusion condition, participants continued to receive the ball approximately one-third of the time. After five minutes the investigation leader entered the room and participants were asked to return to the laboratory. During the immediate post-assessment phase emotional well-being, State-Anxiety-Inventory and Brief Symptom Inventory were assessed. To conclude the post-assessment stage, the Post Game Questionnaire and two manipulation check questions were administered. The session was concluded with the follow-up/debriefing approximately 15 minutes after finishing the experiment by completing the emotional wellbeing scale and debriefing. Participants were then reimbursed for costs $(\$ 50)$.

\subsubsection{Data Analysis}

Statistical analysis was performed using the SPSS 15.0. According to KolmogoroffSmirnov the majority of the variables (18 of 24) were normally distributed, meaning that parametric statistical analysis could be applied. Non-parametric statistical analysis was applied to the correlation analysis of the subsample of the PTSD exclusion condition, due to its small sample size.

\subsection{Results}

The two manipulation check questions showed expected differences between the exclusion and inclusion conditions, independent of PTSD or control group affiliation: felt ignored $(\mathrm{t}=-5.54, \mathrm{df}=30, p=<.001)$ and felt excluded $(\mathrm{t}=-10.08, \mathrm{df}=21, p=<.001$; effect size .69). As life satisfaction showed group differences $(\mathrm{t}=4.35 \mathrm{df}=39, p=.00)$ and years of education also showed a slight group difference $(\mathrm{t}=2.09$, $\mathrm{df}=39, p=.04)$, these variables 
were assumed to be covariates in the subsequent $2 \times 2$ covariance analysis (Table 5 demonstrates findings on group differences controlled for life satisfaction and education levels). 


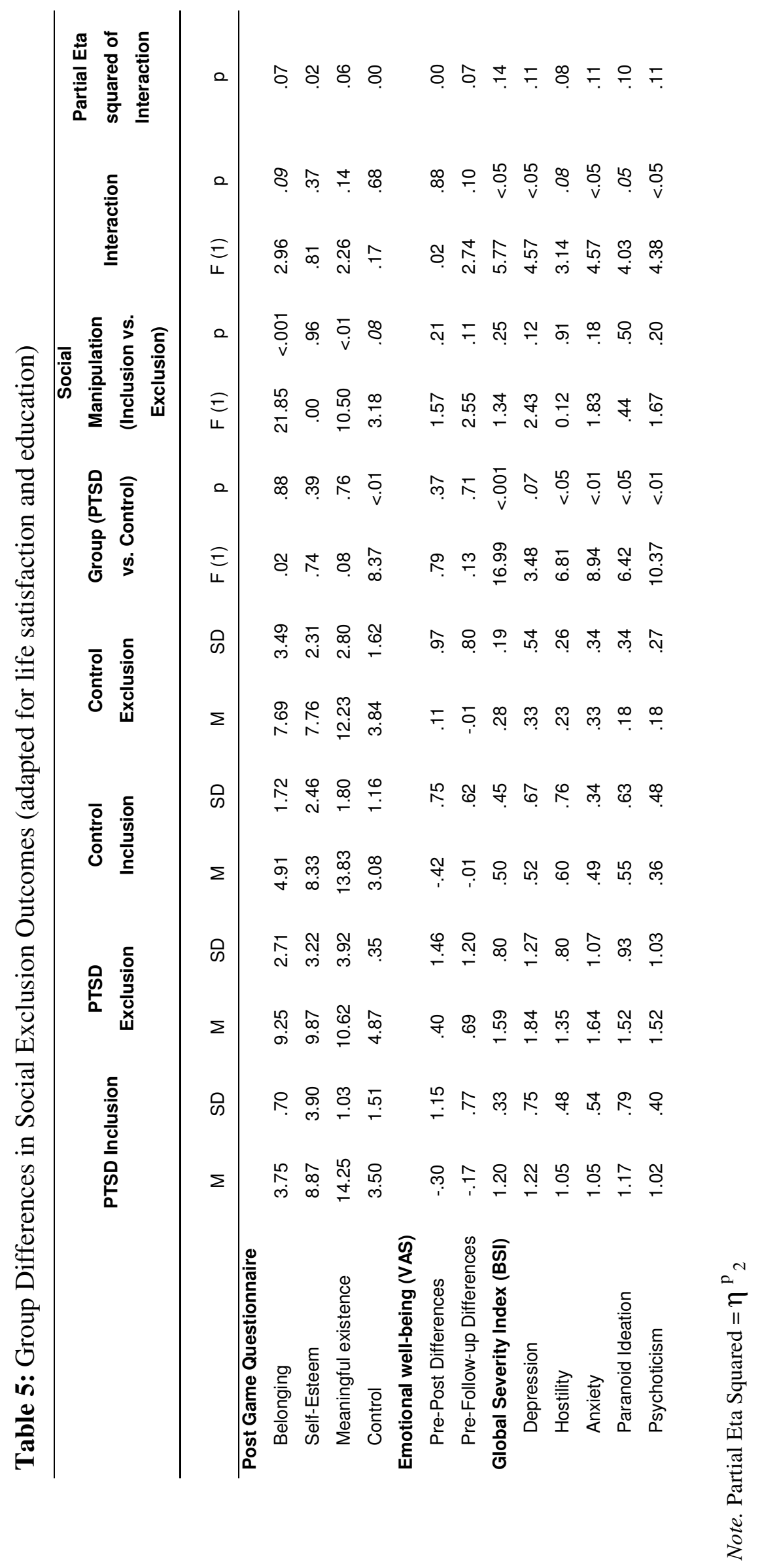


An effect for group (PTSD vs. non-PTSD) was demonstrated in the Post Game Questionnaire subscale of control (the PTSD group showed less feelings of control than the control group), whereas effects of conditions were found in three of the Post Game Questionnaire subscales (excluded participants showed less feelings of belonging, meaningful existence and control than included participants). The belonging subscale showed an interaction trend, indicating PTSD participants in the exclusion condition to feel less belonging than those in all other conditions ${ }^{2}$. No main and only one interaction effect at trend level were found for changes of emotional well-being (as measured by VAS) during and after the experiment. Pre-follow-up differences in well-being were significant at trend level $(\mathrm{p}<.10)$ for the group $\mathrm{x}$ condition interaction, with the excluded PTSD group showing decreased wellbeing above that of the other conditions.

Several psychological symptom and distress indicators suggest main effects for group as well as interaction effects. The BSI subscales of depression, anxiety and psychoticism showed significant interaction effects, while hostility and paranoid ideation showed marginally significant interactions $(\geq .08)$. The PTSD group was more hostile and demonstrated higher levels of paranoid ideation than the control group. All effect sizes of interaction effects remained in the low range, while the BSI total score showed the comparably largest eta value (.14).

Finally, an exploratory analysis with the PTSD exclusion condition subsample $(\mathrm{N}=8)$ (see table 6) was conducted. The following significant correlations were found between independent variables of PTSD severity, self-reported acknowledgement as a victim or survivor and outcomes of the experiment: hyperarousal and less meaningful existence, recognition as victim and elevated belonging values.

\footnotetext{
${ }^{2}$ To verify the stability of results a random subsample of $\mathrm{N}=16$ was taken from the total control group $(\mathrm{N}=25)$ and was compared with the PTSD group. The interaction of PTSD vs. control and social manipulation (exclusion/inclusion) was tested using analysis of variance (ANOVA) and demonstrated a tendency towards significance for belonging $(\mathrm{F}=4.93, \mathrm{df}=1, p=0.05)$ and meaningful existence $(\mathrm{F}=3.02, \mathrm{df}=1, p=0.09)$. No significant effects were found for self-esteem and control.
} 


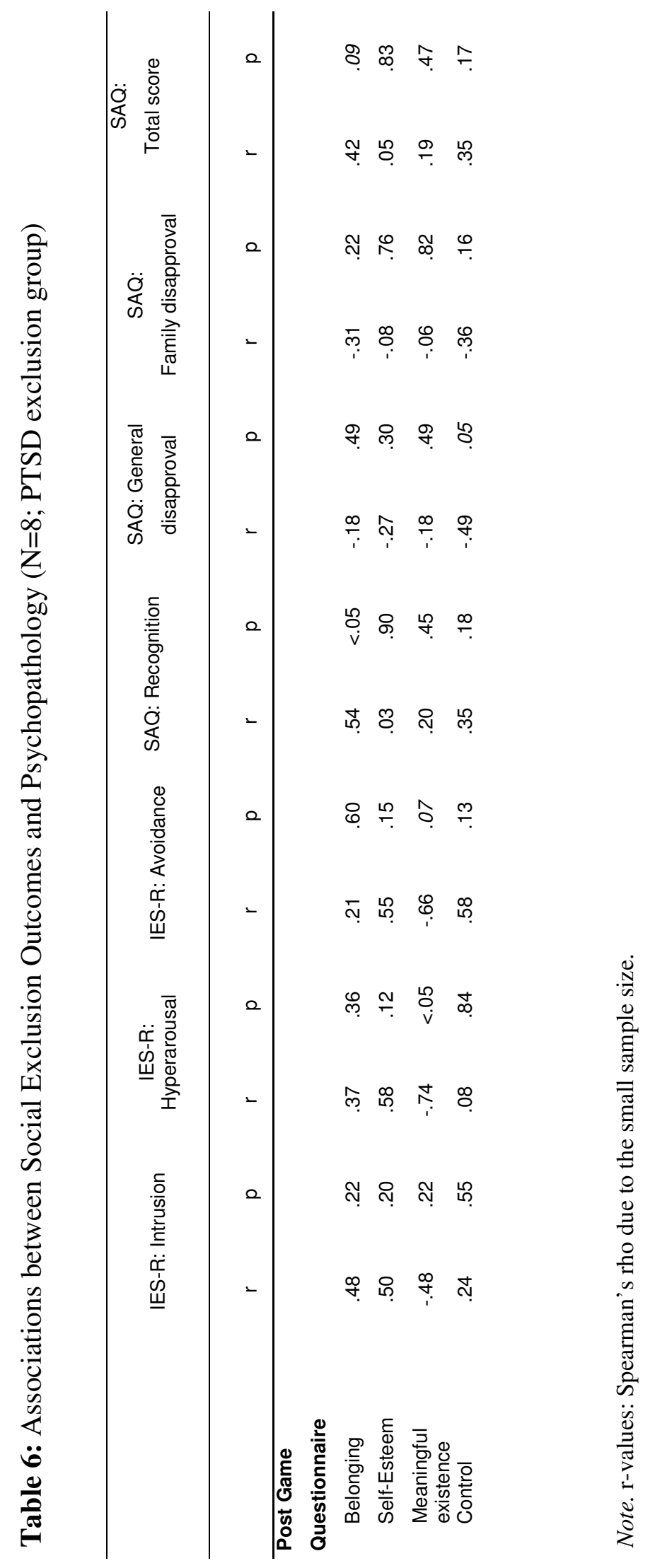




\subsection{Discussion}

The aim of the present experiment was to compare reactions to social exclusion in individuals with PTSD and in non-traumatized controls. It was hypothesized that the PTSD group would show stronger negative outcomes than non-traumatized controls after an experience of social exclusion. The outcome of the research showed the social exclusion experiment in its original behavioral version to be successful, with significant main effects for exclusion vs. inclusion indicating its success. These findings suggest the face-to-face ball tossing game to be a powerful social manipulation tool. It must be noted, however, that the authors of this paper agree with Williams and his colleagues (Williams, 2001; Williams \& Sommer, 1997) that this behavioral version is a highly labor intensive method (due to the recruitment and selection of confidants who must vary in age to present a realistic environment).

The main findings are that the exclusion condition (as operationalized by Williams; 1997) affects three of the four fundamental needs (belonging, meaningful existence and control) both in individuals with PTSD and non-traumatized controls and that these findings are in accordance with prior ball tossing game research (Williams \& Sommer, 1997). Both groups showed less feeling of belonging, meaningful existence and control. It must be noted, however, that the fourth original outcome scale (self-esteem) did not demonstrate significant main differences. The interaction effects (PTSD x exclusion) demonstrated a significance at trend level for only the belonging subscale. Such a finding could be explained by the implementation of the Post Game Questionnaire at the end of the experimental session, as participants should not be influenced by the disclosure of potential social exclusion effects before psychopathology or emotional well-being has been assessed. Therefore, it is plausible that the effects could have been reduced by the employed timeline.

However, based on the single effect found, it may be concluded that individuals with PTSD may be particularly vulnerable to social exclusion in comparison to healthy individuals. A similar non-significant finding was also found for changes in emotional well-being, in that excluded PTSD participants showed a tendency towards additional worsening immediately following the experiment. The current assessment of emotional well-being was included in addition to Williams and colleagues' (2008; Williams \& Sommer, 1997) standard outcome measures for social exclusion as the experience of exclusion is a negative experience, which is expected to have additional distressing effects besides its threat to fundamental needs. Williams (2007) has described some controversy in the literature regarding affect alteration due to social exclusion, in which the effects of increased negative affect and decreased 
positive affect have routinely been found in most studies. The findings of the current research neither support nor discredit either side of the argument on emotional well-being as the findings are not sufficiently robust.

The clearest findings of the current research were the interaction effects of psychopathology measures of depression, anxiety, paranoid ideation and psychoticism. Participants with PTSD showed elevated levels after the social exclusion manipulation, suggesting social exclusion manipulation to lead to extensive impairments of components of mental health in trauma survivors with PTSD. In accordance, it can therefore be concluded, that people with PTSD feel worse after experiencing social exclusion. Importantly, these effects appeared to correlate more with symptomatology (e.g. higher depression), rather than with social psychological indicators.

In summary, the authors conclude that a general assumption of elevated levels of selfperceived social exclusion in PTSD patients can be differentiated by highlighting psychopathological (e.g. fear, anxiety, depression) effects of exclusion. As far as the authors are aware, no other studies have applied the Williams paradigm to PTSD or other clinical groups except for a study by Zadro and colleagues (2006). In this study they examined the detrimental effects of ostracism in high and low socially anxious participants with an online paradigm. It was found that exclusion affected both groups - although the high socially anxious participants recovered some of their needs (as assessed by the Post Game Questionnaire) at a slower rate than the low socially anxious group. Consequently, the current research makes a unique contribution to the area of research.

The present study presents several limitations. First, only ten participants fulfilled the criteria for full PTSD diagnosis and six participants were subsyndromal. The high subsyndromal rate nevertheless suggests that the sample is affected. This has been previously suggested by Schützwohl and Maercker (1999) who demonstrated the subsyndromal PTSD group to have higher levels of predisposition to avoidance, intrusion and hyperarousal when assessed on the Impact of Event Scale. This has been supported in the current study in terms of high scores of the PTSD group on the Impact of Event Scale. The use of subsyndromal patients may be viewed by some as a limitation. However, these findings may also suggest that a clinical PTSD group may react more strongly to social exclusion. Second, the sample size was small and thus may limit the generalizability of findings. A replication of the present study with a larger sample is therefore warranted. Third, the ascertainment of individual coping-strategies to dealing with social exclusion was not possible and this would be an interesting topic for future studies. Fourth, restricted study resources did not allow controlling 
for comorbidity in PTSD. Fifth, another limitation is the lack of a trauma exposed non PTSD control group. The failure to assess additional variables, such as the extent of social isolation of participants before traumatization and the extent of stigmatization after traumatization, must also be noted as a further limitation.

A clinical implication of these findings may be the development of interventions designed to inform patients about such possible changes following traumatization. By increasing awareness of possible negative consequences of experiencing every day situations of exclusion, psychoeducation or interventions may serve as a protective measures against further psychosocial impairments (e.g. social isolation) and other mental health problems (e.g. depressive and anxiety disorders). This could be achieved through cognitive-behavioral techniques which modify negative outcomes of PTSD or social exclusion (e.g. Arntz, Tiesema, \& Kindt, 2007). 


\section{References}

Abramson, L. Y., Seligman, M. E., \& Teasdale, J. D. (1978). Learned helplessness in humans: Critique and reformulation. Journal of Abnormal Psychology, 87, 49-74.

Agnew, Z. K., Bhakoo, K. K., \& Puri, B. K. (2007). The human mirror system: A motor resonance theory of mind-reading. Brain Research Reviews, 54(2), 286-293.

American Psychiatric Association. (1994). Diagnostic and statistical manual of mental disorder (4th Ed.). Washington: American Psychiatric Association.

Arntz, A., Tiesema, M., \& Kindt, M. (2007). Treatment of PTSD: A comparison of imaginal exposure with and without imagery rescripting. Journal of Behavior Therapy and Experimental Psychiatry, 38(4), 345-370.

Aschenbrenner, S., Tucha, O., \& Lange, K. W. (2000). Regensburg Word Fluency Test. Göttingen: Hogrefe.

Augustine, J. R. (1996). Circuitry and functional aspects of the insular lobe in primates including humans. Brain Research Reviews, 22(3), 229-244.

Baron-Cohen, S., Jolliffe, T., Mortimore, C., \& Robertson, M. (1997). Another advanced test of theory of mind: evidence from very high functioning adults with autism or asperger syndrome. Journal of Child Psychology and Psychiatry, 38, 813-822.

Baron-Cohen, S., O'Riordan, M., Stone, V., Jones, R., \& Plaisted, K. (1999). Recognition of faux pas by normally developing children and children with Asperger syndrome or high-functioning autism. Journal of Autism and Developmental Disorders, 29, 407418.

Baron-Cohen, S., Tager-Flusberg, H., \& Cohen, D. J. (2000). Understanding Other Minds: Perspectives from developmental neuroscience. New York: Oxford University Press.

Baron-Cohen, S., Wheelwright, S., Hill, J., Raste, Y., \& Plumb, I. (2001). The "Reading the Mind in the Eyes" Test revised version: a study with normal adults, and adults with Asperger syndrome or high-functioning autism. Journal of Child Psychology and Psychiatry, 42, 241-251. 
Baumeister, R. F., DeWall, C. N., Ciarocco, N. J., \& Twenge, J. M. (2005). Social exclusion impairs self-regulation. Journal of Personality and Social Psychology, 88(4), 589-604.

Baumeister, R. F., \& Leary, M. R. (1995). The need to belong: Desire for interpersonal attachments as a fundamental human motivation. Psychological Bulletin, 117, 497-529.

Baumeister, R. F., Twenge, J. M., \& Nuss, C. K. (2002). Effects of social exclusion on cognitive processes: anticipated aloneness reduces intelligent thought. Journal of Personality and Social Psychology, 83(4), 817-827.

Blair, R. J. (2005). Responding to the emotions of others: dissociating forms of empathy through the study of typical and psychiatric populations. Consciousness and Cognition, 14(4), 698-718.

Blair, J., Sellars, C., Strickland, I., Clark, F., Williams, A., Smith, M., et al. (1996). Theory of mind in the psychopath. The American Journal of Forensic Psychiatry, 7, 15-25.

Blanchard, E. B., Hickling, E. J., Taylor, A. E., \& Loos, W. (1995). Psychiatric morbidity associated with motor vehicle accidents. Journal of Nervous and Mental Disease, 183, 495-504.

Blanchard, E. B., Hickling, E. J., Taylor, A. N., Loos, W. R., Forneris, C. A., \& Jaccard, J. (1996). Who develops PTSD from motor vehicle accidents? Behaviour Research and Therapy, 34(1), 1-10.

Bloom, B. L., White, S. W., \& Asher, S. J. (1979). Marital disruption as a stressful life event. In G. Levinger \& O. C. Moles (Eds.), Divorce and Separation: Context, Causes and Consequences (pp. 184-200). New York: Basic Books.

Bolton, E. E., Litz, B. T., Glenn, D. M., Orsillo, S., \& Roemer, L. (2002). The Impact of Homecoming Reception on the Adaption of Peacekeepers Following Deployment. Military Psychology, 14(3), 241-251.

Borja, S. E., Callahan, J. L., \& Long, P. J. (2006). Positive and negative adjustment and social support of sexual assault survivors. Journal of Traumatic Stress, 19(6), 905-914. 
Bradley, J. R., \& Cartwright, S. (2002). Social support, job stress, health, and job satisfaction among nurses in the United Kingdom. International Journal of Stress Management, 9, 163-182.

Brewin, C. R. (2005). Risk factor effect sizes in PTSD: what this means for intervention. Journal of Trauma and Dissociation, 6(2), 123-130.

Brewin, C. R., Andrews, B., \& Valentine, J. D. (2000). Meta-analysis of risk factors for posttraumatic stress disorder in trauma-exposed adults. Journal of Consulting and Clinical Psychology, 68(5), 748-766.

Brune, M. (2001). Social cognition and psychopathology in an evolutionary perspective. Current status and proposals for research. Psychopathology, 34(2), 85-94.

Brune, M., \& Brune-Cohrs, U. (2006). Theory of mind-evolution, ontogeny, brain mechanisms and psychopathology. Neuroscience and Biobehavioral Reviews, 30, 437455.

Cacioppo, J. T., Hawkley, L. C., \& Bernston, G. G. (2003). The anatomy of loneliness. Current Directions in Psychological Science, 12, 71-74.

Carr, L., Iacoboni, M., Dubeau, M. C., Mazziotta, J. C., \& Lenzi, G. L. (2003). Neural mechanisms of empathy in humans: a relay from neural systems for imitation to limbic areas. Proceedings of the National Academy of Sciences of the United States of America, 100(9), 5497-5502.

Charuvastra, A., \& Cloitre, M. (2008). Social bonds and posttraumatic stress disorder. Annual Review of Psychology, 59, 301-328.

Cook, J. D., \& Bickman, L. (1990). Social support and psychological symptomatology following a natural disaster. Journal of Traumatic Stress, 3, 541-556.

Cook, J. M., Riggs, D. S., Thompson, R., Coyne, J. C., \& Sheikh, J. I. (2004). Posttraumatic stress disorder and current relationship functioning among World War II ex-prisoners of war. Journal of Family Psychology, 18, 36-45.

Cordova, M. J., Cunningham, L. L. C., Carlson, C. R., \& Andrykowski, M. A. (2001). Social constraints, cognitive processing, and adjustment to breast cancer. Journal of Consulting and Clinical Psychology, 69, 706-711. 
Cosmides, L. (1989). The logic of social exchange: Has natural selection shaped how human reason? Studies with the Wason Selection Task. Cognition, 31, 187-276.

Davidson, J. R., Hughes, D., Blazer, D. G., \& George, L. K. (1991). Post-traumatic stress disorder in the community: An epidemiological study. Psychological Medicine, 21, 713-721.

Davis, M. H. (1980). A multidimensional approach to individual differences in empathy. Catalog of Selected Documents in Psychology, 10, 85-100.

Davis, M. H. (1983). Measuring individual differences in empathy: Evidence for a multidimensional approach. Journal of Personality and Social Psychology, 44, $113-$ 126.

De Vignemont, F., \& Singer, T. (2006). The empathic brain: how, when and why? Trends in Cognitive Science, 10, 435-441.

Decety, J., \& Jackson, P. L. (2004). The functional architecture of human empathy. Behavioral and Cognitive Neuroscience Reviews, 3(2), 71-100.

Decety, J., \& Jackson, P.L. (2006). A Social-Neuroscience Perspective on Empathy. Current Directions in Psychological Science, 15, 54-58.

DePrince, A. P. (2005). Social Cognition and Revictimization Risk. Journal of Trauma and Dissociation, 6(1), 125-141.

Derogatis, L. R. (1992). BSI: Administration, scoring, and procedures manual-II (2nd Ed.). Baltimore, MD: Clinical Psychometric Research.

Diener, E., Emmons, R. A., Larsen, R. J., \& Griffin, S. (1985). The Satisfaction with Life Scale. Journal of Personality Assessment, 49, 71-75.

Dilling, H., Mombour, W., \& Schmidt, M. H. (2000). Internationale Klassifikation psychischer Störungen. ICD-10 Kapitel V (F). Klinisch-diagnostische Leitlinien. Bern: Verlag Hans Huber.

Eisenberger, N. I., Lieberman, M. D., \& Williams, K. D. (2003). Does rejection hurt? An FMRI study of social exclusion. Science, 302(5643), 290-292. 
First, M. B., Gibbon, M., Spitzer, R. L., \& Williams, J. B. W. (1996). Users Guide for the Structured Clinical Interview for DSM-IV Axis I Disorder - Research Version. New York: Biometrics Research.

Freyd, J.J. (1994). Betrayal-trauma: Traumatic amnesia as an adaptive response to childhood abuse. Ethics \& Behavior, 4, 307-329.

Frith, C. D. (1999). Interacting minds-A biological basis. Science, 286, 1692-1695.

Gallese, V. (2003). The Roots of Empathy: The Shared Manifold Hypothesis and the Neural Basis of Intersubjectivity. Psychopathology, 36, 171-180.

Gallese, V., \& Goldman, A. (1998). Mirror neurons and the simulation theory of mindreading. TICS, 2, 493-501.

Gardner, W. L., Pickett, C. L., \& Knowles, M. (2005). Social snacking and shielding: using social symbols, selves, and surrogates in the service of belonging needs. In K. D. Williams, J. P. Forgas \& W. V. Hippel (Eds.), The Social Outcast: Ostracism, Social Exclusion, Rejection, and Bullying. (pp. 227-242). New York: Psychological Press.

Ginzburg, K., Solomon, Z., Dekel, R., \& Neria, Y. (2003). Battlefield functioning and chronic PTSD: associations with perceived self efficacy and causal attribution. Personality and Individual Differences, 34, 463-476.

Gray, M. J., Pumphrey, J. E., \& Lombardo, T. W. (2003). The relationship between dispositional pessimistic attributional style versus trauma-specific attributions and PTSD symptoms. Journal of Anxiety Disorders, 17, 289-303.

Gregory, C., Lough, S., Stone, V., Erzinclioglu, S., Martin, L., Baron-Cohen, S., et al. (2002). Theory of mind in patients with frontal variant frontotemporal dementia and Alzheimer's disease: theoretical and practical implications. Brain, 125(Pt 4), 752-764.

Gruter, M., \& Masters, R. D. (1986). Ostracism as a social and biological phenomenon: An introduction. Ethology and Sociobiology, 7, 149-158.

Guay, S., Billette, V., \& Marchand, A. (2006). Exploring the links between posttraumatic stress disorder and social support: processes and potential research avenues. Journal of Traumatic Stress, 19(3), 327-338. 
Haeny, C., Nietlisbach, G., \& Maercker, A. (in press). Veränderte Selbstwahrnehmung bei Posttraumatischer Belastungsstörung: Die Beispiele der „Transparency-Illusion“ und des „Self-Handicapping“. Trauma und Gewalt.

Haker, H., \& Rossler, W. Empathy in schizophrenia: Reduced resonance. Submitted.

Hatfield, E., Cacioppo, J., \& Rapson, R. (1994). Emotional Contagion. New York: Cambridge University Press.

Heyman, R.E., Sayers, S.L., \& Bellack, A.S. (1994). Global marital satisfaction versus marital adjustment: An empirical comparison of three measures. Journal of Family Psychology, 8, 432-446.

Hickling, E. J., \& Blanchard, E. B. (1992). Post-Traumatic Stress Disorder and Motor Vehicle Accidents. Journal of Anxiety Disorders, 6, 285-291.

Iacoboni, M., \& Dapretto, M. (2006). The mirror neuron system and the consequences of its dysfunction. Nature Reviews Neuroscience, 7(12), 942-951.

Jankowski, M. K., Schnurr, P. P., Adams, G. A., Green, B. L., Ford, J. D., \& Friedman, M. J. (2004). A mediational model of PTSD in World War II veterans exposed to mustard gas. Journal of Traumatic Stress, 17, 303-310.

Jensen, A., \& Rohwer, J. (1966). The stroop color-word test: A review. Acta Psychologica, 25, 36-93.

Johnson, D. R., Rosenheck, R., Fontana, A., Lubin, H., Charney, D., \& Southwick, S. (1996). Outcome of intensive inpatient treatment for combat-related posttraumatic stress disorder. The American Journal of Psychiatry, 153(6), 771-777.

Johnson, S. M., \& Greenberg, L. S. (1994). The Heart of the Matter: Perspectives on Emotion in Marital Therapy. New York: Brunner/Mazel.

Jolliffe, D., \& Farrington, D. P. (2004). Empathy and offending: A systematic review and meta-analysis. Aggression and Violent Behavior, 9, 441-176.

Jones, B., Müller, J., \& Maercker, A. (2006). Trauma and Posttraumatic Reactions in German Development Aid Workers: Prevalences and Relationship to Social Acknowledgment. International Journal of Social Psychiatry, 52, 91-100. 
Kallstrom-Fuqua, A. C., Weston, R., \& Marshall, L. L. (2004). Childhood and Adolescent Sexual Abuse of Community Women: Mediated Effects on Psychological Distress and Social Relationships. Journal of Consulting and Clinical Psychology, 72(6), 980-992.

Kelley, H. (1967). Attribution theory in social psychology. In D. Levine (Ed.), Nebraska Symposium on Motivation. Lincoln: University of Nebraska Press.

Keysers, C., \& Gazzola, V. (2007). Integrating simulation and theory of mind: from self to social cognition. Trends in Cognitive Science, 11, 194-196.

Krill, A. L., Platek, S. M., \& Wathne, K. (2008). Feelings of control during social exclusion are partly accounted for by empathizing personality. Personality and Individual Differences, 45, 684-688.

Kurzban, R., \& Leary, M. R. (2001). Evolutionary Origins of Stigmatization: The Functions of Social Exclusion. Psychological Bulletin, 127(2), 187-208.

Laffaye, C., Cavella, S., Drescher, K., \& Rosen, C. (2008). Relationships among PTSD symptoms, social support, and support source in veterans with chronic PTSD. Journal of Traumatic Stress, 21(4), 394-401.

Leary, M. R. (1990). Responses to social exclusion: Social anxiety, jealousy, loneliness, depression, and low self-esteem. Journal of Social and Clinical Psychology, 9, 221229.

Lee, L., Harkness, K. L., Sabbagh, M. A., \& Jacobson, J. A. (2005). Mental state decoding abilities in clinical depression. Journal of Affective Disorders, 86(2-3), 247-258.

Leslie, A. (1987). Pretence and representation: The origins of "theory of mind". Psychological Review, 94, 412-426.

Leslie, K. R., Johnson-Frey, S. H., \& Grafton, S. T. (2004). Functional imaging of face and hand imitation: towards a motor theory of empathy. Neuroimage, 21, 601-607.

Lough, S., \& Hodges, J. R. (2002). Measuring and modifying abnormal social cognition in frontal variant frontotemporal dementia. Journal of Psychosomatic Research, 53, 639646. 
Maercker, A. (Ed.). (2003). Therapie der posttraumatischen Belastungsstörungen. Berlin: Springer.

Maercker, A. (2006). Victims' experiences in context: Social conditions of mental sequelae. In Weisser Ring (Ed.). Victim forever? Baden-Baden: Nomos (in German language).

Maercker, A. (2008a). A Social Facilitation Model of Posttraumatic Stress Disorder. University of Zurich: Unpublished manuscript.

Maercker, A. (2008b). Towards a New Social Facilitation Model of PTSD. Paper 39. Berlin: International Congress of Psychology, July 2008.

Maercker, A., \& Mehr, A. (2006). What if victims read a newspaper report about their victimisation? A study on relationship to PTSD symptoms in crime victims. European Psychologist, 11, 137-142.

Maercker, A., \& Müller, J. (2004). Social Acknowledgment as a Victim or Survivor: A Scale to Measure a Recovery Factor of PTSD. Journal of Traumatic Stress, 17, 345-351.

Maercker, A., Schützwohl, M., \& Solomon, Z. (1999). Posttraumatic stress disorder: A lifespan developmental perspective. Seattle: Hogrefe \& Huber.

Major, B., \& O'Brian, T. (2005). The Social Psychology of Stigma. Annual Review of Psychology, 56, 393-421.

Maner, J. K., DeWall, C. N., Baumeister, R. F., \& Schaller, M. (2007). Does social exclusion motivate interpersonal reconnection? Resolving the "porcupine problem". Journal of Personality and Social Psychology, 92(1), 42-55.

McFarlane, A. C. (1988). The aetiology of post-traumatic stress disorders following a natural disaster. British Journal of Psychiatry, 152, 116-121.

McFarlane, A. C., \& Bookless, C. (2001). The effect of PTSD on interpersonal relationships: issues for emergency service workers. Sexual and Relationship Therapy, 16, 261-267.

Mikulincer, M., \& Solomon, Z. (1988). Attributional style and combat-related posttraumatic stress disorder. Journal of Abnormal Psychology, 97, 308-313. 
Montag, C., Heinz, A., Kunz, D., \& Gallinat, J. (2007). Self-reported empathic abilities in schizophrenia. Schizophrenia Research, 92(1-3), 85-89.

Moskowitz, G. B. (2005). Social Cognition. Understanding Self and Others. New York: The Guilford Press.

Müller, J., \& Maercker, A. (2006). Disclosure und wahrgenommene gesellschaftliche Wertschätzung als Opfer als Prädiktoren von PTB bei Kriminalitätsopfern. Zeitschrift für Klinische Psychologie und Psychotherapie, 35, 49-58.

Müller, J., Moergeli, H., \& Maercker, A. (2008). Disclosure and Social Acknowledgement as Predictors of Recovery from Posttraumatic Stress: A Longitudinal Study in Crime Victims. The Canadian Journal of Psychiatry, 53(3), 160-168.

Nietlisbach, G., \& Maercker, A. (in press). Social Cognition and Interpersonal Impairments in Trauma Survivors with PTSD. Journal of Aggression, Maltreatment \& Trauma.

Nietlisbach, G., \& Maercker, A. (2009). Effects of Social Exclusion in Trauma Survivors with PTSD. Submitted.

Nietlisbach, G., Maercker, A., Rössler, W., \& Haker, H. (2008). Are Empathic Abilities Impaired in Posttraumatic Stress Disorder? Submitted.

Olff, M., Langeland, W., \& Gersons, B. P. (2005). The psychobiology of PTSD: coping with trauma. Psychoneuroendocrinology, 30, 974-982.

Orth, U., Cahill, S. P., Foa, F. B., \& Maercker, A. (2008). Anger and Posttraumatic Stress Disorder symptoms in crime victims: A longitudinal analysis. Journal of Consulting \& Clinical Psychology, 76(2), 208-218.

Orth, U., Montada, L., \& Maercker, A. (2006). Feelings of revenge, retaliation motive, and posttraumatic stress reactions in victims of violent crimes. Journal of Interpersonal Violence, 21, 221-243.

Ozer, E. J., Best, S. R., Lipsey, T. L., \& Weiss, D. S. (2003). Predictors of posttraumatic stress disorder and symptoms in adults: a meta-analysis. Psychological Bulletin, 129, 52-73. 
Penn, D. L., Corrigan, P. W., Bentall, R. P., Racenstein, J. M., \& Newman, L. (1997). Social cognition in schizophrenia. Psychological Bulletin, 121(1), 114-132.

Perret, E. (1974). The left frontal lobe of man and the suppression of habitual responses in verbal categorical behaviour. Neuropsychologia, 12, 323-330.

Platek, S. M., Critton, S. R., Myers, T. E., \& Gallup, G. G. (2003). Contagious yawning: the role of self-awareness and mental state attribution. Brain research. Cognitive Brain Research, 17, 223-227.

Porter, C. A., \& Long, P. J. (1999). Locus of Control and Adjustment in Female Adult Survivors of Childhood Sexual Abuse. Journal of Child Sexual Abuse, 8(1), 3-25.

Premack, D., \& Woodruff, G. (1978). Does the chimpanzee have a "theory of mind"? The Behavioral and Brain Sciences, 4, 515-526.

Preston, S. D., \& De Waal, F. B. M. (2002). Empathy: Its ultimate and proximate bases. Behavioral and Brain Sciences, 25, 1-72.

Regard, M., Strauss, E., \& Knapp, P. (1982). Children's production on verbal and non-verbal fluency tasks. Perceptual and Motor Skills, 55, 839-844.

Regehr, C., Cadell, S., \& Jansen, K. (1999). Perceptions of control and long-term recovery from rape. American Journal of Orthopsychiatry, 69(1), 110-115.

Richell, R. A., Mitchell, D. G., Newman, C., Leonard, A., Baron-Cohen, S., \& Blair, R. J. (2003). Theory of mind and psychopathy: can psychopathic individuals read the 'language of the eyes'? Neuropsychologia, 41, 523-526.

Riggs, D. S., Byrne, C. A., Weathers, F. W., \& Litz, B. T. (1998). The Quality of the Intimate Relationships of Male Vietnam Veterans: Problems Associated with Posttraumatic Stress Disorder. Journal of Traumatic Stress, 11, 87-101.

Rizzolatti, G., \& Craighero, L. (2004). The mirror neuron system. Annu Rev Neurosci, 27, 169-192.

Rizzolatti, G., Fadiga, L., Fogassi, L., \& Gallese, V. (2002). From mirror neurons to imitation, facts, and speculations. In A. N. Meltzoff \& W. Prinz (Eds.), The imitative mind: development, evolution, and brain bases (pp. 247-266): Cambridge University Press. 
Rizzolatti, G., Fadiga, L., Gallese, V., \& Fogassi, L. (1996). Premotor cortex and the recognition of motor actions. Brain research. Cognitive Brain Research, 3, 131-141.

Rogers, K., Dziobek, I., Hassenstab, J., Wolf, O. T., \& Convit, A. (2007). Who cares? Revisiting empathy in Asperger syndrome. J Autism Dev.Disord., 37(4), 709-715.

Rössler, W., \& Lackus, B. (1986). Cognitve Disorders in Schizophrenics Viewed from the Attribution Theory. European Archives of Psychiatry and Neurological Sciences, 235, 382-387.

Rotter, J. B. (1966). Generalized expectancies for internal versus external control of reinforcement. Psychological Monographs: General and Applied, 80.

Scarpa, A., Haden, S. C., \& Hurley, J. (2006). Community violence victimization and symptoms of posttraumatic stress disorder: the moderating effects of coping and social support. Journal of Interpersonal Violence, 21(4), 446-469.

Schachter, S. (1959). The psychology of affiliation. Standford, CA: Standford University Press.

Schnurr, P. P., Lunney, C. A., \& Sengupta, A. (2004). Risk factors for the development versus maintenance of posttraumatic stress disorder. Journal of Traumatic Stress, 17(2), 8595.

Schürmann, M., Hesse, M. D., Stephan, K. E., Saarela, M., Zilles, K., Hari, R., \& Fink, G.B. (2005). Yearning to yawn: the neural basis of contagious yawning. Neuroimage, 24, $1260-1264$.

Schützwohl, M., \& Maercker, A. (1999). Effects of Varying Diagnostic Criteria for Posttraumatic Stress Disorder Are Endorsing the Concept of Partial PTSD. Journal of Traumatic Stress, 12(1), 155-165.

Schützwohl, M., \& Maercker, A. (2000). Anger in former East German political prisoners: Relationship to posttraumatic stress reactions and social support. Journal of Nervous and Mental Diseases, 188, 483-489.

Senju, A., Maeda, M., Kikuchi, Y., Hasegawa, T., Tojo, Y., \& Osanai, H. (2007). Absence of contagious yawning in children with autism spectrum disorder. Biology Letters, 3(6), 706-708. 
Singer, T. (2006). The neuronal basis and ontogeny of empathy and mind reading: Review of literature and implications for future research. Neuroscience and Biobehavioral Reviews, 30(6), 855-863.

Singer, T., Seymour, B., O'Doherty, J. P., Stephan, K. E., Dolan, R. J., \& Frith, C. D. (2006). Empathic neural responses are modulated by the perceived fairness of others. Nature, 439(7075), 466-469.

Soderstrom, H. (2003). Psychopathy as a disorder of empathy. European Child \& Adolescent Psychiatry 12(5), 249-252.

Solomon, Z., Mikulincer, M., Freid, B., \& Wosner, Y. (1987). Family characteristics and posttraumatic stress disorder: a follow-up of Israeli combat stress reaction causalities. Family Process, 26, 383-394.

Solomon, Z., Waysman, M., \& Mikulincer, M. (1990). Family functioning, perceived social support, and combat-related psychopathology: The moderating role of loneliness. Journal of Social and Clinical Psychology, 9, 456-472.

Spanier, G.B. (1976). Measuring dydic adjustment: New scales for assessing the quality of marriage and similar dyads. Journal of Sex and Marital Therapy, 38, 15-28.

Spinella, M. (2005). Prefrontal substrates of empathy: psychometric evidence in a community sample. Biological psychology, 70(3), 175-181.

Strauss, E., Sherman, E., \& Spreen, O. (2006). A compendium of neuropsychological test: administration, norms, and commentary (3rd ed.). Oxford: Oxford University Press.

Stroop, J. (1935). Studies of interference in serial verbal reactions. Journal of Experimental Psychology, 18, 643-661.

Twenge, J. M., Baumeister, R. F., DeWall, C. N., Ciarocco, N. J., \& Bartels, J. M. (2007). Social exclusion decreases prosocial behavior. Journal of Personality and Social Psychology, 92(1), 56-66.

Twenge, J. M., Baumeister, R. F., Tice, D. M., \& Stucke, T. S. (2001). If you can't join them, beat them: effects of social exclusion on aggressive behavior. Journal of Personality and Social Psychology, 81(6), 1058-1069. 
Uddin, L. Q., Iacoboni, M., Lange, C., \& Keenan, J. P. (2007). The self and social cognition: the role of cortical midline structures and mirror neurons. Trends in Cognitive Science, $11,153-157$.

Ullman, S.E. (2003). Social Reactions to Child Abuse Disclosures: A Critical Review. Journal of Child Sexual Abuse, 12(1), 89-121.

Vollm, B. A., Taylor, A. N., Richardson, P., Corcoran, R., Stirling, J., McKie, S., et al. (2006). Neuronal correlates of theory of mind and empathy: a functional magnetic resonance imaging study in a nonverbal task. Neuroimage, 29(1), 90-98.

Wakabayashi, A., Baron-Cohen, S., Goldenfeld, N., Delaney, J., Fine, D., \& Smith, R. (2006). Development of short forms of the Empathy Quotient (EQ-Short) and Systemizing Quotient (SQ-Short). Personality and Individual Differences, 41(5), 929-940.

Warburton, W. A., Williams, K. D., \& Cairns, D. R. (2006). When ostracism leads to aggression: The moderating effects of control deprivation. Journal of Experimental Social Psychology, 42, 213-220.

Weiss, D. S., \& Marmar, C. R. (1996). The Impact of Event Scale - Revised. In J. P. Wilson \& T. M. Keane (Eds.), Assessing psychological trauma and PTSD (pp. 399-411). New York: Guilford.

Williams, J. H., Whiten, A., Suddendorf, T., \& Perrett, D. I. (2001). Imitation, mirror neurons and autism. Neuroscience and Behavioral Reviews, 25(4), 287-295.

Williams, K. D. (1997). Social ostracism. In R. Kowalski (Ed.), Aversive interpersonal behaviors (pp. 133-170). New York: Plenum.

Williams, K. D. (2001). Ostracism: The power of silence. New York: Guilford Press.

Williams, K. D. (2007). Ostracism. Annual Review of Psychology, 58, 425-452.

Williams, K. D. (in press). Ostracism: A Temporal Need-Threat Model. In M. Zanna (Ed.), Advances in Experimental Social Psychology. New York Elsevier.

Williams, K. D., \& Jarvis, B. (2006). Cyberball: A program for use in research on interpersonal ostracism and acceptance. Behavior Research Methods, 38, 174-180. 
Williams, K. D., \& Sommer, K. L. (1997). Social ostracism by coworkers: Does rejection lead to social loafing or compensation? Personality \& Social Psychology Bulletin, 23(693706).

Williams, K. D., \& Zadro, L. (2001). Ostracism: On being ignored, excluded, and rejected. In M. Leary (Ed.), Interpersonal rejection (pp. 21-53). New York: Oxford University Press.

Williams, K. D., Cheung, C. K., \& Choi, W. (2000). Cyberostracism: effects of being ignored over the Internet. Journal of Personality and Social Psychology, 79(5), 748-762.

Williams, K. D., Forgas, J. P., Von Hippel, W., \& Zadro, L. (2005). The Social Outcast. An Overview. In K. D. Williams, J. P. Forgas \& W. Von Hippel (Eds.), The Social Outcast. Ostracism, Social Exclusion, Rejection, and Bullying (pp. 1-16). New York: Psychology Press.

Williams, K. D., Govan, C. L., Croker, V., Tynan, D., Cruickshank, M., \& Lam, A. (2002). Investigations into differences between social and cyberostracism. Group Dynamics: Theory, Research, and Practice, 6, 65-77.

Wimmer, H., \& Perner, J. (1983). Beliefs about beliefs: Representation and constraining function of wrong beliefs in young children's understanding of deception. Cognition, $13,103-128$.

Yoshihama, M., \& Horrocks, J. (2005). Relationship between emotional numbing and arousal symptoms in American women of Japanese descent who experienced interpersonal victimization. Anxiety Disorders, 19, 443-459.

Zadro, L., Boland, C., \& Richardson, R. (2006). How long does it last? The persistence of the effects of ostracism in the socially anxious. Journal of Experimental Social Psychology, 42, 692-697.

Zadro, L., Williams, K. D., \& Richardson, R. (2004). How low can you go? Ostracism by a computer is sufficient to lower self-reported levels of belonging, control, self-esteem, and meaningful existence. Journal of Experimental Social Psychology, 40, 560-567. 